ديناميكية تطور متغيرات الخطوة وعلاقتها بتغيرات تركيز حض اللاكتيك و إنزيمي LDH \& CPK خلال سباق · · عم عدو

د/أحمد نصر المراغي د د/ محمد محمد عبد الهادي مقدمة ومشكلة البحث :-

إن سباق . .عم عدو يلقب بالسباق القاتل أو كما هو متعارف عليه " قاتل الرجال " وذللك نظر الأنه لا

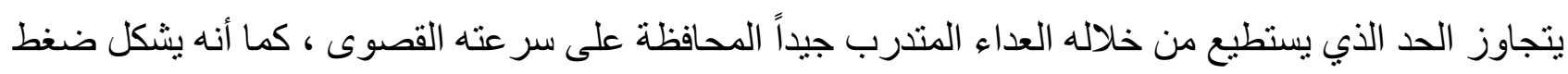
كبير على أجهزة الجسم مع إجهاد بشكل غير ثابت و على الأخص في المرحلة الختامية من السباق ـ ( l l) وتعتمد كفاءة العدو على تتاغم المتغيرات البيوميكانيكية بين مراحله الأربعه والتي تشمل مرحلة البدء ومرحلة تز ايد السرعة ومرحلة الحفاظ على السر عة القصوى و أيضا مرحلة تناقص السر عة.

حيث يتحدد الزمن اللازم للعدو وفقاً للعديد من المتغيرات البيوميكانيكية و التي تتمثل في سر عة العدو وبعض

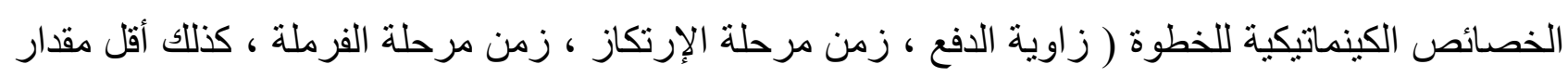

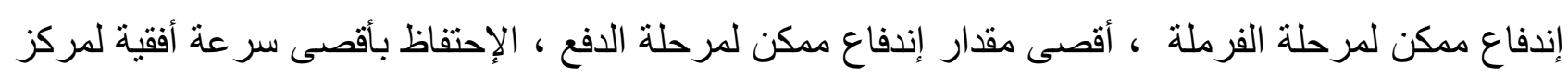

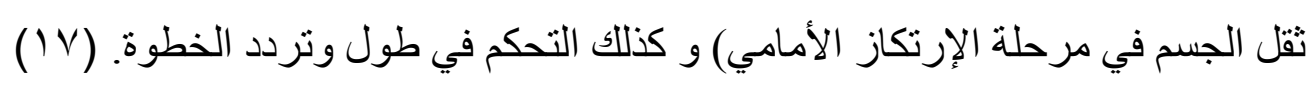

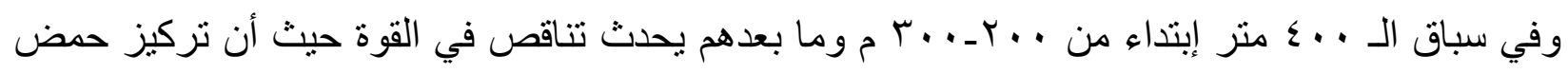

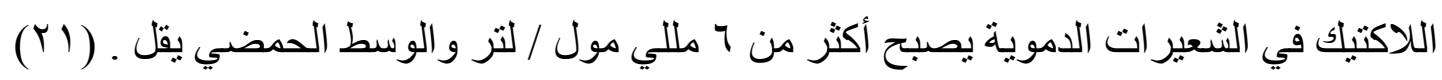
ففي جميع مسابقات العدو السريعة التي تستمر لـدة ( ( Y ) دقيقة والتي تعتمد على النظام اللاكتيكي يزداد

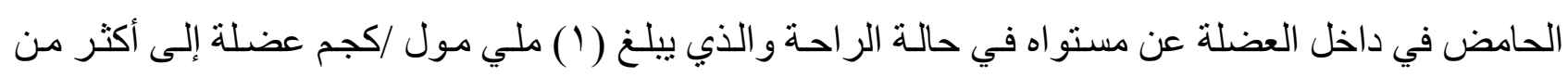
(V) . ملي مول /كجم عضلة (Yo)

ويعتمد النجاح في سباق . .ـ م عدو إلي حد كبير على قدرة المتسابق على إنتاج الطاقة عن طريق الجلكزة

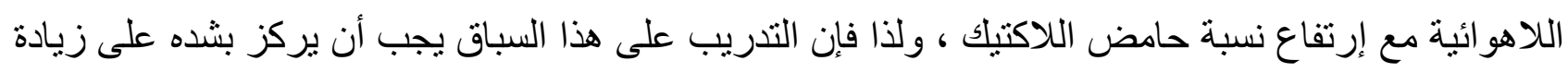

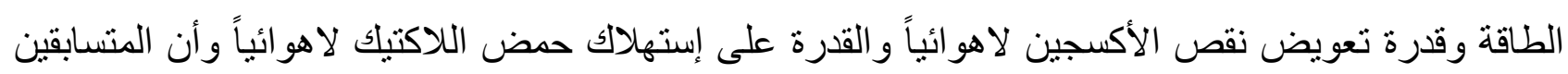

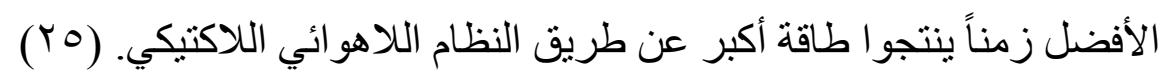
فالعدائين الأكثر تدريباً لديهم قدرة أعلى في الحفاظ على السرعة القصوى بدرجة أكبر من العدائين الأقل

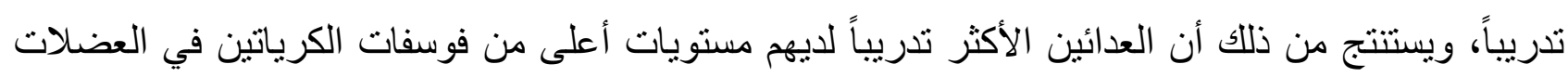

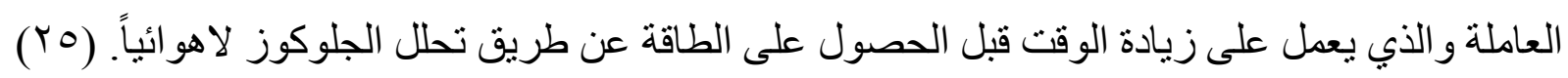


وتعد الإنزيمات عبارة عن جزيئات بروتينية تعمل كحافزات بيولوجية لزيادة معدل التفاعلات البيوكيميائية

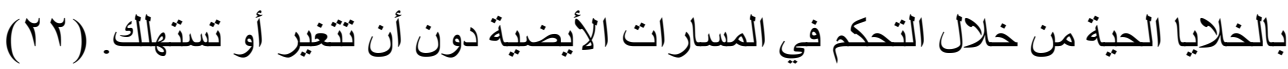
ويعرف إنزيم كرياتين فسفو كينيزCPK بأنه إنزيم ثنائي يحفز الفسفرة العكسية لأدينوزين ثنائي الفوسفات عن طريق تحلل فوسفات الكرياتين لإنتاج الطاقة وفوسفات غير عضوي من أجل تكوين ثلاثي أدينوزين

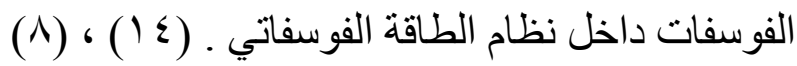

و إنزيم لاكتيك ديهيدروجينيز LDH هو إنزيم يحفز من تحويل البيروفات الي لاكتات (ويسمى أيضا نازع

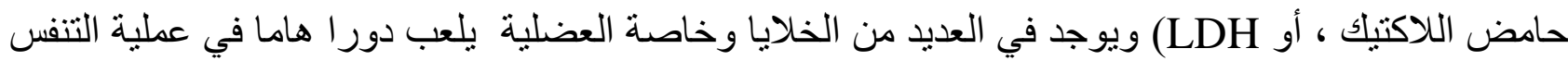

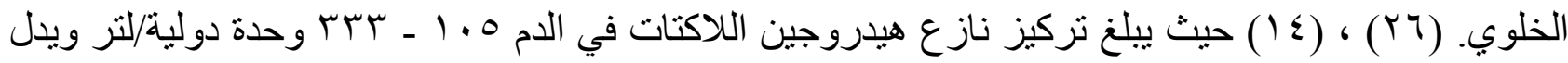
إرتفاع التركيز على ضرر بأنسجة معينة. (YV) (rV)

ونظر الإرتباط زمن سباق ال . .ـ متر بكفاءة العدو خلال مر احل السباق وكذلك تأثير المتغيرات الميكانيكية لخطوة العداء فى هذه الكفاءة كما أنها تعتبر من أهم العوامل المؤثرة على السرعة، وأيضا إرتباط المتغيرات الإنزيمية قيد البحث بصورة مباثرة بإنتاج الطاقة و التفاعلات البيوكيميائية الداخلية للخلايا خلال العدو و إختلاف تركيز حامض اللاكتيك منذ البداية وكلما زاد زمن الإستمر ار في العدو.

الأمر الذى دفع الباحثان الى دراسة تأثير التغير فى تركيز إنزيمى كرياتين فسفوكينيز و لاكتيك ديهيدروجينيز وحامض اللاكتيك وما يصاحب ذلك من تغيير على تكنيك الخطوة نتيجة لهذه التغيرات الداخلية ومحاولة تحديد ديناميكية هذا التطور خلال مقاطع السباق أى كل ... متر لسباق ... متر وكذلك إعطاء صورة واضحة للددربين و اللاعبين على حد سو اء عن طبيعة الجهد الذى يذله اللاعب أثناء السباق وما يصاحبه من تغيرات فى الجوانب الوظيفية للإستفادة منها فى وضع البرامج التدريبية وتطوير مستويات اللاعبين وقابليتهم البدنية

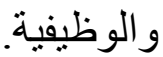

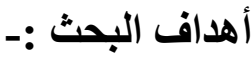

يهدف البحث الى در اسة ديناميكية نطور وتحديد المتغيرات البيوميكانيكية للخطوة وتغير ات تركيز حض اللاكتيك و إنزيمي LDH \& CPK خلال سباق . . عم عدو من خلال ما يلى :-

ا ـ التعرف على العلاقة بين متغيرات الخطوة وتغير ات تركيز حمض اللاكتيك و إنزيمي LDH \& CPK

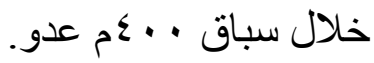

r. التعرف على الفروق فى متغيرات الخطوة وتركيز حمض اللاكتيك و إنزيمي LDH \& CPK خلال

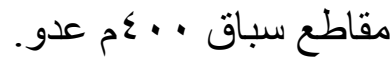


ا . هنالك علاقة ارتباط معنوية بين متغير ات الخطوة وتغيرات تركيز حمض اللاكتيك و إنزيمي &DH CPK خلال سباق • . ع عدو.

Y. . هنالك فروق ذات دلالة معنوية فى متغيرات الخطوة وتركيز حمض اللاكتيك و إنزيمي LDH \& CPK خلال مقاطع سباق · · ع عدو.

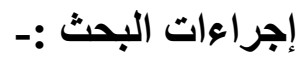

منهج البحث :- إستخدم الباحثان المنهج الوصفى لملائمته لطبيعة البحث . مجالات البحث:

المجال المكانى: ميدان ومضمار ألعاب القوى بكلية التربية الرياضية للبنين جامعة الإسكندرية.

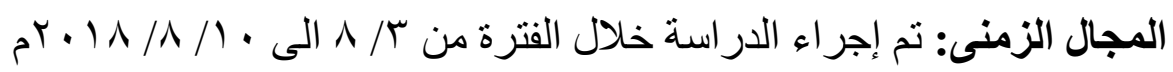
المجال البشرى: متسابقي · . ع متر عدو بمنطقتي الإسكندرية والجيزة لألعاب القوى . عينة البحث: تم إختيار عينة البحث بالطريقة العدية من منسابقي ، . ع متر عدو من منطقة الإسكندرية لألعاب القوى و عددهم (9 لاعبين) من أندية ( الزمالك ، سموحة ، الجياد ، طلبة المدارس ، الإتحاد السكندري ) و التوصيف الإحصائى لعينة البحث يوضحها جدول (1).

جدول ( ( ) التوصيف الإحصائي لعينة البحث فى القياسات الاساسية البيوكيميائية وزمن سباق · . ع متر (ن = 9)

\begin{tabular}{|c|c|c|c|c|c|c|c|}
\hline التفرطح & الالتواء معامل & المعيارى ال المعرف & المستوسط المسبى & 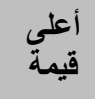 & 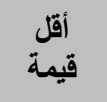 & القياسات & b \\
\hline l, ^ro & $1, \varepsilon r \mu$ & $r, \ldots$ & $19,7 V$ & $r \varepsilon$ & 11 & السن (سنة) & \multirow{3}{*}{ الأقياساتية } \\
\hline$\cdot, 9 \vee 1$ & $\cdot, V T T_{-}$ & $\varepsilon, 0 \leqslant$. & $11 \cdot, 11$ & 111 & $|v|$ & الطول (سم) & \\
\hline$\cdot, 007_{-}$ & $\cdot, \vee \wedge १$ & $0, \leqslant \leqslant \wedge$ & $V Y, \cdot V$ & Ar & 77 & الوزن (كجم) & \\
\hline$\cdot, \Gamma / 0_{-}$ & $\cdot, r v \cdot-$ & $7,7) \leqslant$ & VI,TV & $\Lambda$ & 7. & النبض فى الراحة (نبضة/ق) & \multirow{6}{*}{ والفيوليولية القياتية } \\
\hline $1, \cdot \vee 9_{-}$ & $\cdot$, Aro & $\wedge, 7 \uparrow$. & $117,7 \mathrm{~V}$ & r. & 11. & ضغط الر احة الانقباضي (ملل زئبق) & \\
\hline$\cdot, \mathrm{V} r \mathrm{O}$ & $1, T r$. & $\varepsilon, \Sigma)$ & VY, Y & $\wedge$. & $v \cdot$ & ضغط الر احة الانبساطي (ملل زئبق) & \\
\hline $1, \leqslant Y \cdot-$ & $\cdot, r \leq \varepsilon$ & $11 r, 791$ & rON,Yr & ors & rT. & انزيم كرياتين فوسفوكاينيز CPK فى الراحة (u/l) & \\
\hline $1, r q \wedge$ & $\cdot, \wedge \leq \uparrow$ & $\vee 0, \wedge) \leq$ & 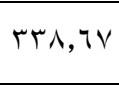 & $\leq 9 \leq$ & rTs & انـزيم لاكتيـك ديهيـدروجينيز & \\
\hline $1, \wedge \wedge 9$ & $1, \varepsilon \wedge$ & $\vee, \cdot 1 \leq$ & $10, \mathrm{~V} \Lambda$ & r & 1. & تركيز حامض اللاكتيك في الراحة (mg/l) & \\
\hline •,rIr- & $\cdot, \wedge \backslash \wedge$ & 1,094 & $0 \leqslant, 19$ & $00, \times 1$ & 01,11 & \multicolumn{2}{|c|}{ زمن سباق · . ع متر (ث) } \\
\hline
\end{tabular}




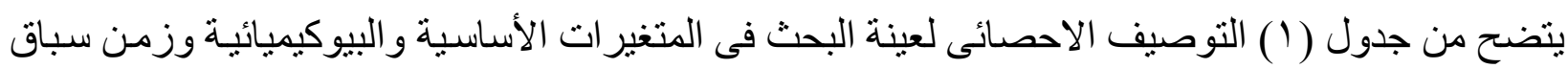

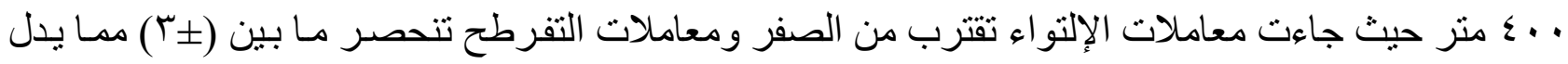
على اعتدالية القيم و عدم التشتت وتجانس أفر اد العينة من منسابقي . . ع متر عدو.

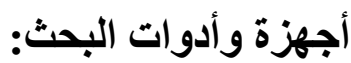

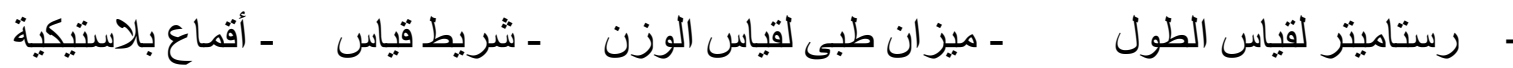
-

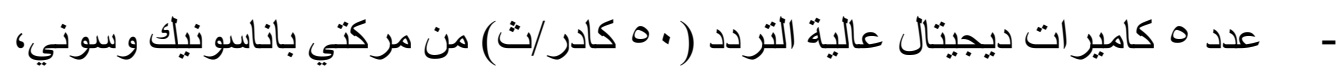

- جهاز فصل الدم Centrifuge Hitch - جهازي تحليل حامض اللاكتيك و الانزيمات

Dimension \& Biosystem Fully Automated Chemical Analyzer

$$
\text { - }
$$

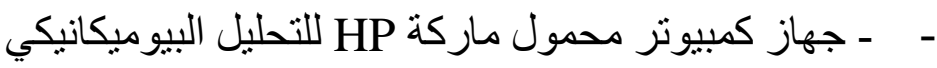

- برنامج التحليل الحركى (DartFish Software Team Pro 6).

$$
\text { قياسات البحث :- }
$$

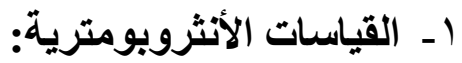

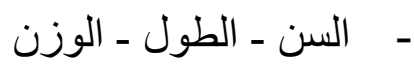

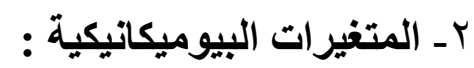

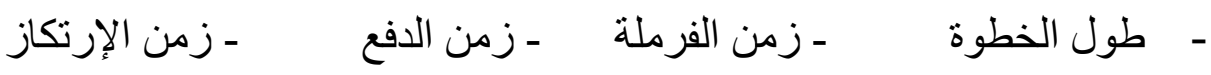

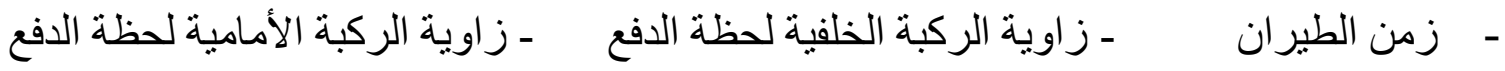

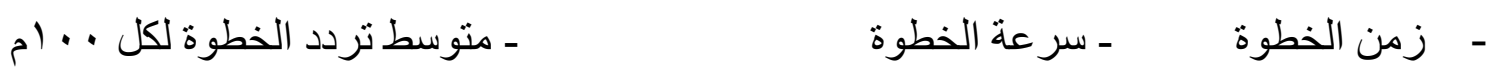

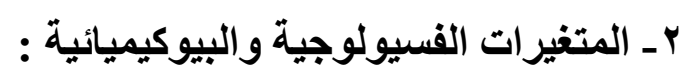

- النبض فى الر احة (نبضة/ق) ضغئط الر احة الانقباضي و الانبساطى (ملل زئبق)

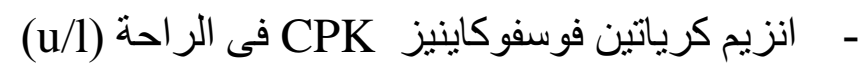

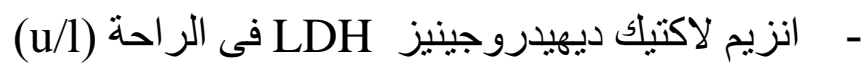
- - تركيز حامض اللاكتيك في الر احة (mg/1) 


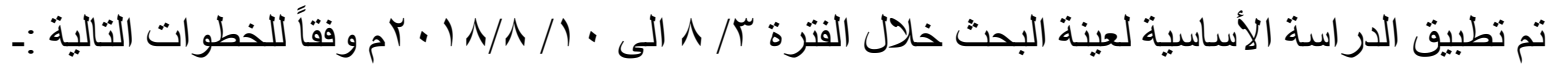
أـ تجهيز المتسابقين : يتم تسجيل البيانات الأساسية الخاصة بكل لاعب (السن، الطول، الوزن) ثم قياس

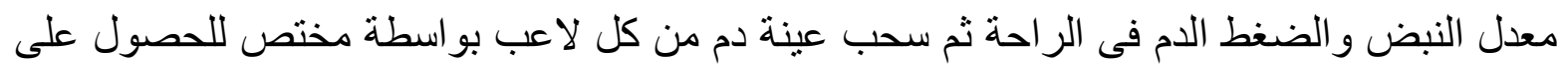
تركيز حمض اللاكتيك و إنزيمي LDH \& CPK أثناء الراحة ثم يقوم اللاعب بالإحماء لمدة 10 دقيقة ثم تجهيز اللاعب للتصوير من خلال وضع علامات عاكسة على المفاصل . بـ اجراء قياسات تركيز حض اللاكتيك وإنزيمي LDH \& CPK خلال مراحل السباق: تم اجر اء هذا

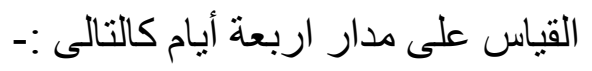
- اليوم الاول يتم قياس زمن سباق . . ع متر وسحب عينة الدم بعد السباق مباثرة بمدة من م الى V دقائق.

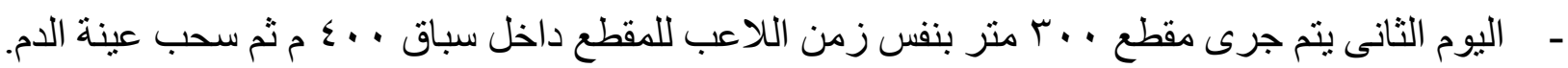

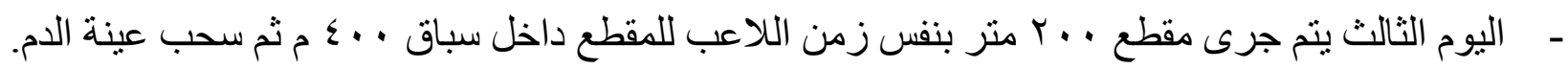

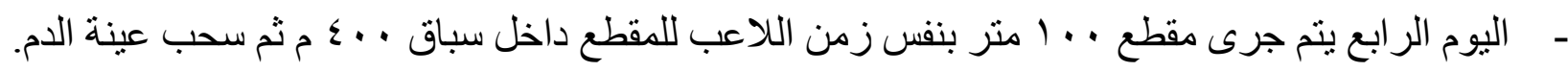

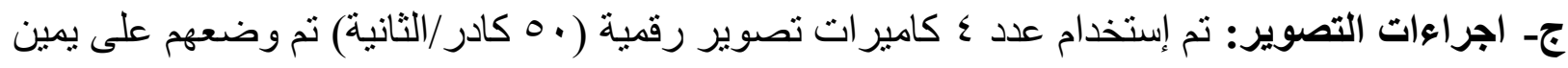
العداء (خارج المضمار) بحيث تكون الكاميرا الأولى على بعد (•0 متر) من خط البداية ، و الكاميرا

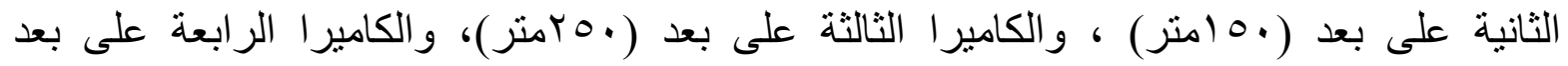

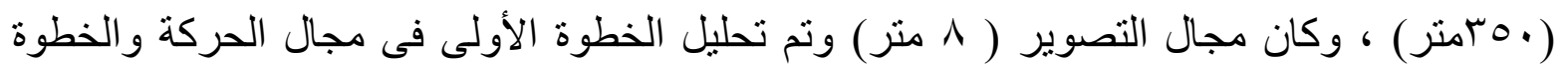

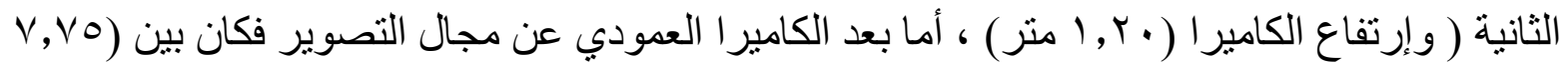

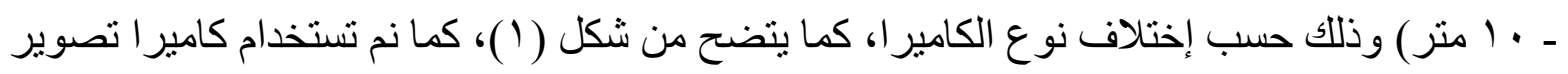

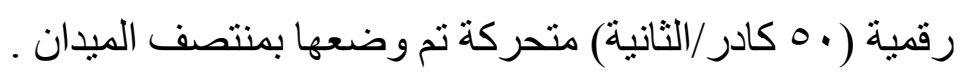

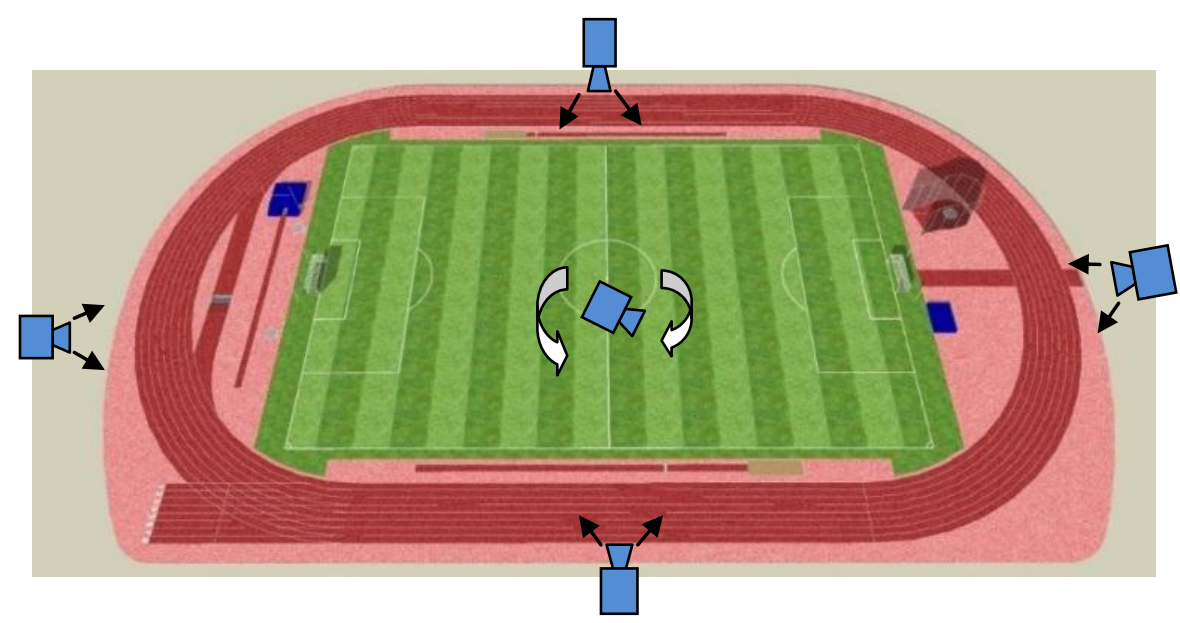

شكل ( (1) يوضح توزيع كاميرات التصوير لمقاطع سباق . . ؛ متر عدو 
ج- إجراءات التحليل الحركى: بعد إنتهاء تصوير مقاطع سباق . ـ متر عدو تم تفريخ فيديوهات التصوير من الكامير ات وتتزيلها على الكمبيوتر واخضـاعها للتحليل الحركى باستخدام برنـامج DartFish Software 6 Team Pro 6 لمعالجتها إحصائياً.

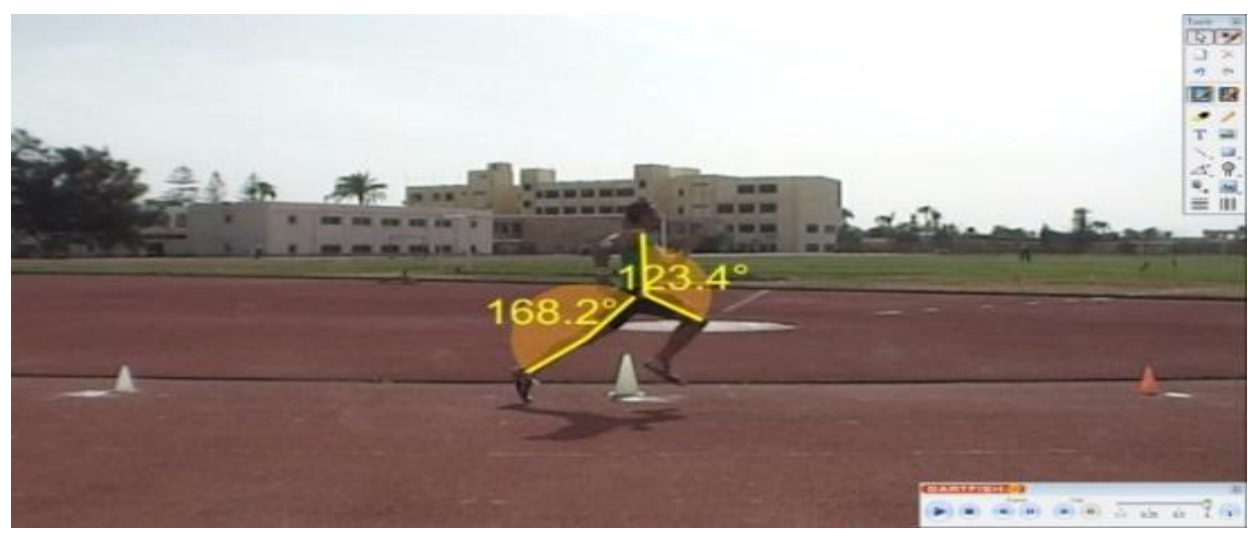

شكل (Y) يوضح زوايا الرجلين ومجال الحركة لإحدى الكاميرات

ا ـ المعالجـات الإحصـائية:تمـت معالجـة البيانـات إحصـائياً عن طريـق الحاسـب الآلى بإسـتخدام البرنـامج الإحصـائى SPSS PASW Statistics 20 للحصول على المعالجـات الإحصـائية الناليـة ( المتوسط الحسـى ، الإنحر اف المعيـارى ، معامل الإلتو اء ، معـاملات الإرتبـاط "ر" لبيرسون ، تحليل التبـاين احادى الاتجاه ، إختبار أقل فرق معنوى لبنفرونى) 
جدول (r) التوصيف الإحصائي فى القياسات البيوكيميائية خلال مقاطع سباق . . ؛ متر (ن = 9)

\begin{tabular}{|c|c|c|c|c|c|c|c|}
\hline التفرطح & الالتواء معامل & الانحر اف المعيارى & المستوسطي & قأعلي & قأقلة & \multicolumn{2}{|c|}{ القياسات } \\
\hline $1, \leqslant r \cdot-$ & $\cdot, r \leq \varepsilon$ & 114,791 & roN, r r & Ors & rr. & في الراحة & \multirow{5}{*}{$\begin{array}{c}\text { فوسفوكاينيز كرياتين } \\
\text { (u/l) }\end{array}$} \\
\hline $1, \cdot \wedge \varepsilon_{-}$ & $\cdot, 110$ & $1 \cdot r, \Lambda .$. & r & oro & $r \leq 1$ & . . امتر & \\
\hline$\cdot, \leqslant \wedge \Lambda_{-}$ &., $0 \mathrm{VV}$ & $111,01 \mathrm{~V}$ & Or $\leqslant, \varepsilon \varepsilon$ & Nr. & rqA & . . امتر & \\
\hline I, $\vee \vee \cdot-$ & $\cdot, 1 \leq 0_{-}$ & YYI,AAV & $7 \Upsilon \leqslant, \varepsilon \varepsilon$ & qrr & rol & . . . متر & \\
\hline $1,9 \vee 9$ &., .01 & rov,09r & $7.1,07$ & qr. & r97 & . . عتر & \\
\hline $1, r q \wedge$ & $\cdot, \wedge \leq \nearrow$ & $\vee 0, \wedge) \leq$ & עז,T & $\leqslant 9 \leqslant$ & TrE & في الراحة & \multirow{5}{*}{$\begin{array}{c}\text { ديهيديم لاكتيكيز } 2 \text { دDH } \\
\text { LDH } \\
\text { (u/l) }\end{array}$} \\
\hline $1,190_{-}$ & $\cdot, \cdot \leq 7$ & $7 \vee, Y q q$ & $r \leq r, 11$ & $\varepsilon \Gamma$ & rri & .. (متر & \\
\hline$\cdot, \cdot \leq \varepsilon$ & $\cdot$, , & אسז, & $\leq \leq 7,11$ & 711 & rqr & . . . متر & \\
\hline$\cdot, r V \cdot$ & $\cdot, 901$ & $1 \leq \vee, \wedge \ldots$ & $0 T 7, Y Y$ & 100 & $\varepsilon .9$ & . . امتر & \\
\hline$r, 1.9$ & 1,701 & & س & VAr & rov & . . عمتر & \\
\hline $1, \wedge \wedge 9$ & $1, \leqslant \Lambda$. & $v, \cdot 1 \leq$ & $10, \mathrm{VA}$ & r & 1. & في الراحة & \multirow{5}{*}{ تركيز حامض اللاكتيك } \\
\hline I, QTr _ & $\cdot, \cdot 1 \cdot$ & $\varepsilon, 000$ & $r, \ldots$ & YV & 10 & . . امتر & \\
\hline$\cdot, \vee \vee 9 \varepsilon_{-}$ & $\cdot, \wedge T 1$ & 0,490 & 77,11 & vo & 71 & . . . متر & \\
\hline $1, \cdot r \Lambda_{-}$ &., .09 & $T, 1 \wedge V$ & $\mid r \leqslant, 07$ & $1 \Gamma \varepsilon$ & 117 & . . امتر & \\
\hline., $0 \times 1-$ & $\cdot, \cdot \leq 1$ & $\wedge, \wedge \vee \leqslant$ & $|Y|, 7 V$ & 1To & 1.9 & . . متر & \\
\hline
\end{tabular}

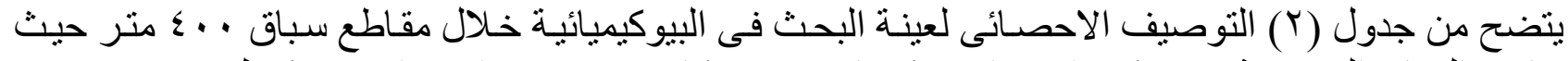

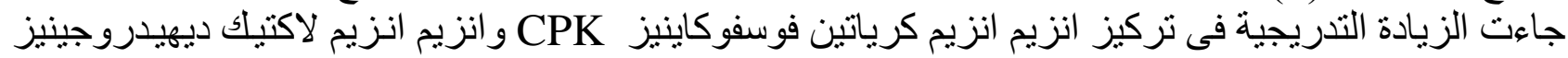

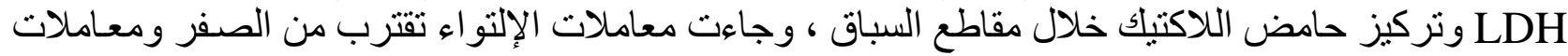

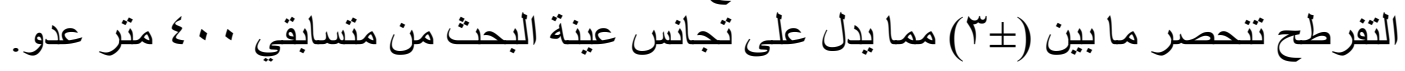

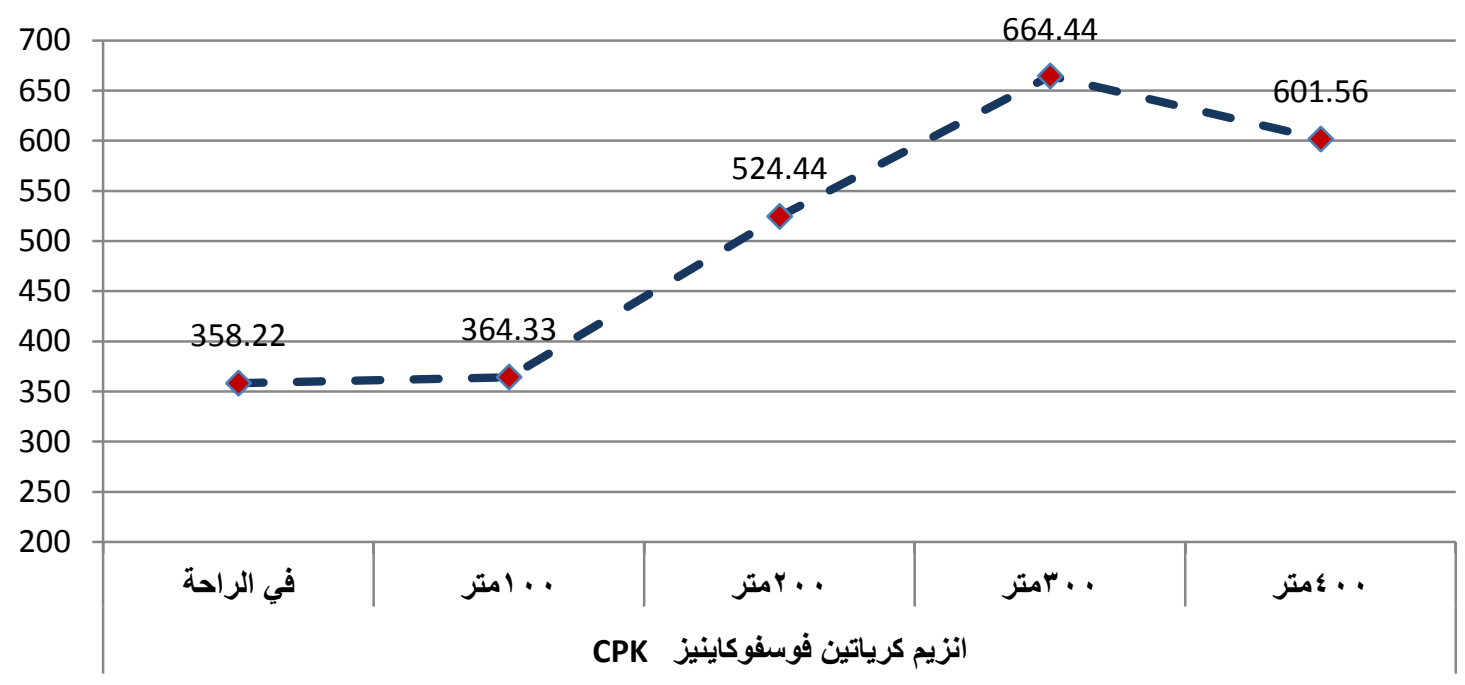



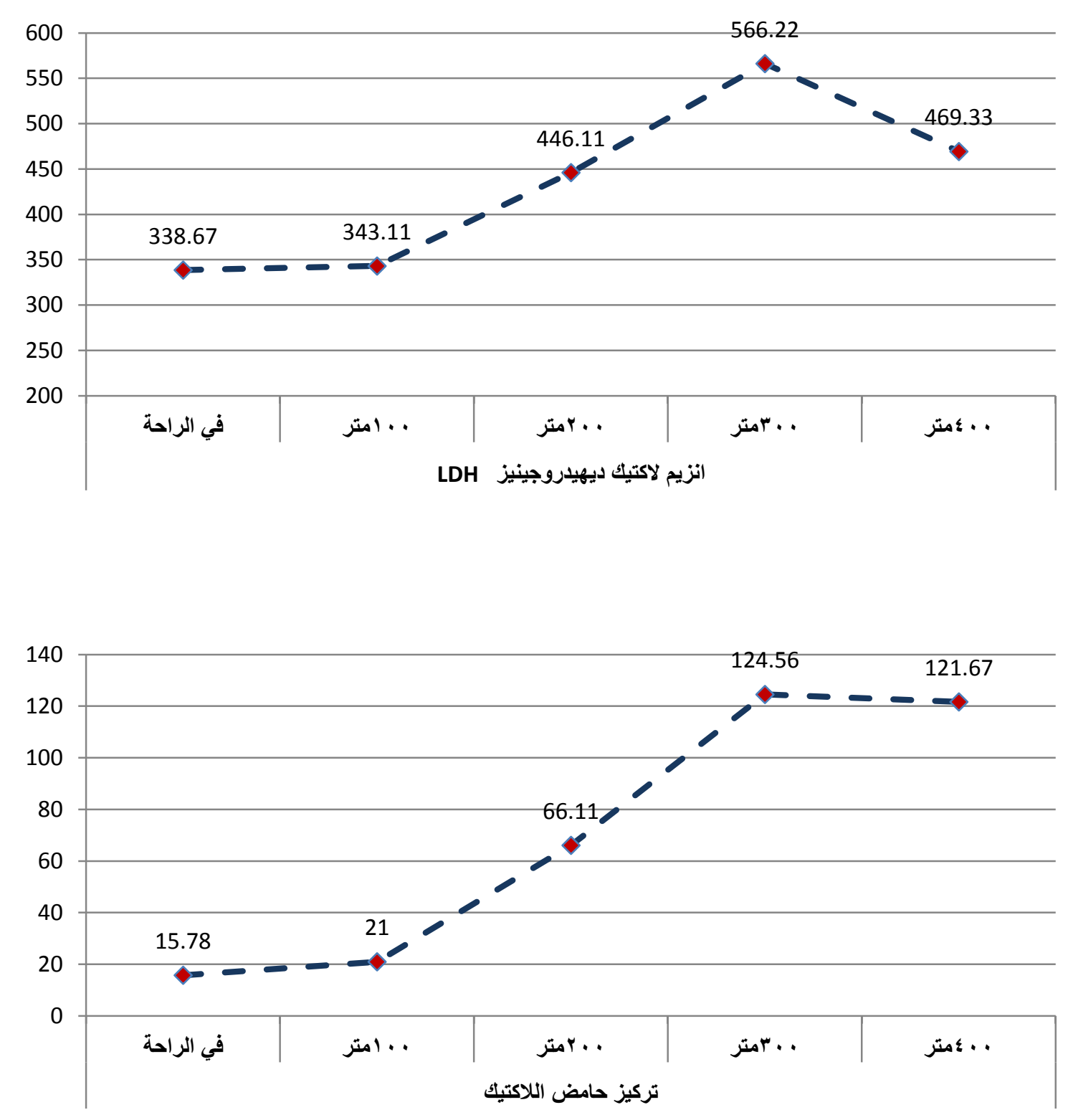

شكل (ץ) المتوسط الحسابى فى القياسات البيوكيميائية خلال مقاطع سباق . ؛ متر 
جدول (") التوصيف الإحصائي فى بعض القياسات البيوميكاتيكية وزمن مقاطع سباق . . ؛ متر (ن = 9)

\begin{tabular}{|c|c|c|c|c|c|c|c|}
\hline التفرطح & الالتواء & الانحريارى & المتسابى المسط & قأعلي & قأقلّ & \multicolumn{2}{|c|}{ القياسـات } \\
\hline $1, r \wedge 0_{-}$ & $\cdot, Y \backslash V$ & $11, I V Y$ & $1 \wedge \wedge, \ldots$ & $r \cdot \varepsilon$ & IVT,O & \multicolumn{2}{|c|}{ عدد الخطوات (عدد) } \\
\hline 1,YOY_ & $\cdot, \cdot V_{1}$ & שצו & rTIT & r,r & 1,97 & \multicolumn{2}{|c|}{ متوسط طول الخطوة (م) } \\
\hline 1,179 & $\cdot, r \cdot v$ & $\cdot, 10 \leq$ & $r, \leqslant \vee$ & $r, V T$ & r,Y & \multicolumn{2}{|c|}{ متوسط تردد الخطوة (خ/ث) } \\
\hline$\cdot, \cdot \leq r_{-}$ & $\cdot, 9 \ldots$ & $\cdot, r Y I$ & $\vee, r q$ & V,Ar & $\vee, 1 \wedge$ & \multicolumn{2}{|c|}{ متوسط السر عة (م/ث) } \\
\hline$\cdot M_{M}$ & $\cdot, \wedge \backslash \Lambda_{-}$ & $1,09 \pi$ & $0 \leqslant, 19$ & $00, \vee 1$ & 01,11 & \multicolumn{2}{|c|}{ زمن سباق . . ك منر (ث) } \\
\hline$\cdot, 7 Y q_{-}$ & $\cdot, 0 \wedge 1$ & 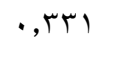 & $|r, \wedge|$ & 1ז,ו & $|r, r|$ & ·. · الاولى & \multirow{4}{*}{ 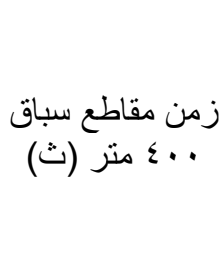 } \\
\hline$\cdot, \mid \vee 7_{-}$ & $\cdot$,TYK & $\cdot, \leqslant 9 \wedge$ & IY, $\Sigma V$ & $|r, r|$ & $11, \vee \wedge$ & · · · م الثانية & \\
\hline $1, T V Y$ & $\cdot$, OYT & .07 & M & $1 \leq, 9 \leq$ & $|r, q|$ & 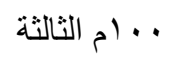 & \\
\hline$\cdot, 0 \wedge \varepsilon_{-}$ & $\cdot, r q)$ & $\cdot, 9 \wedge 1$ & $10, .9$ & $17, \vee \wedge$ & Ir,vA & . . ام الرابعة & \\
\hline
\end{tabular}

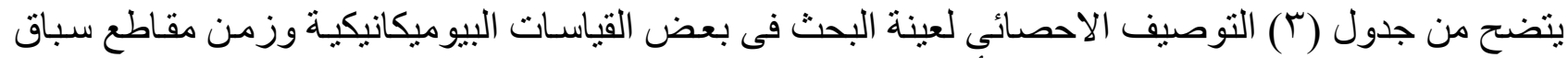

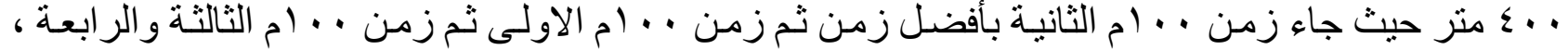

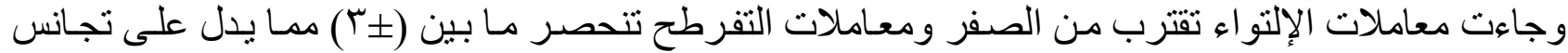

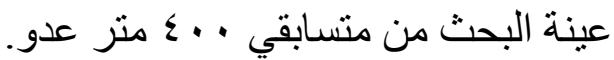

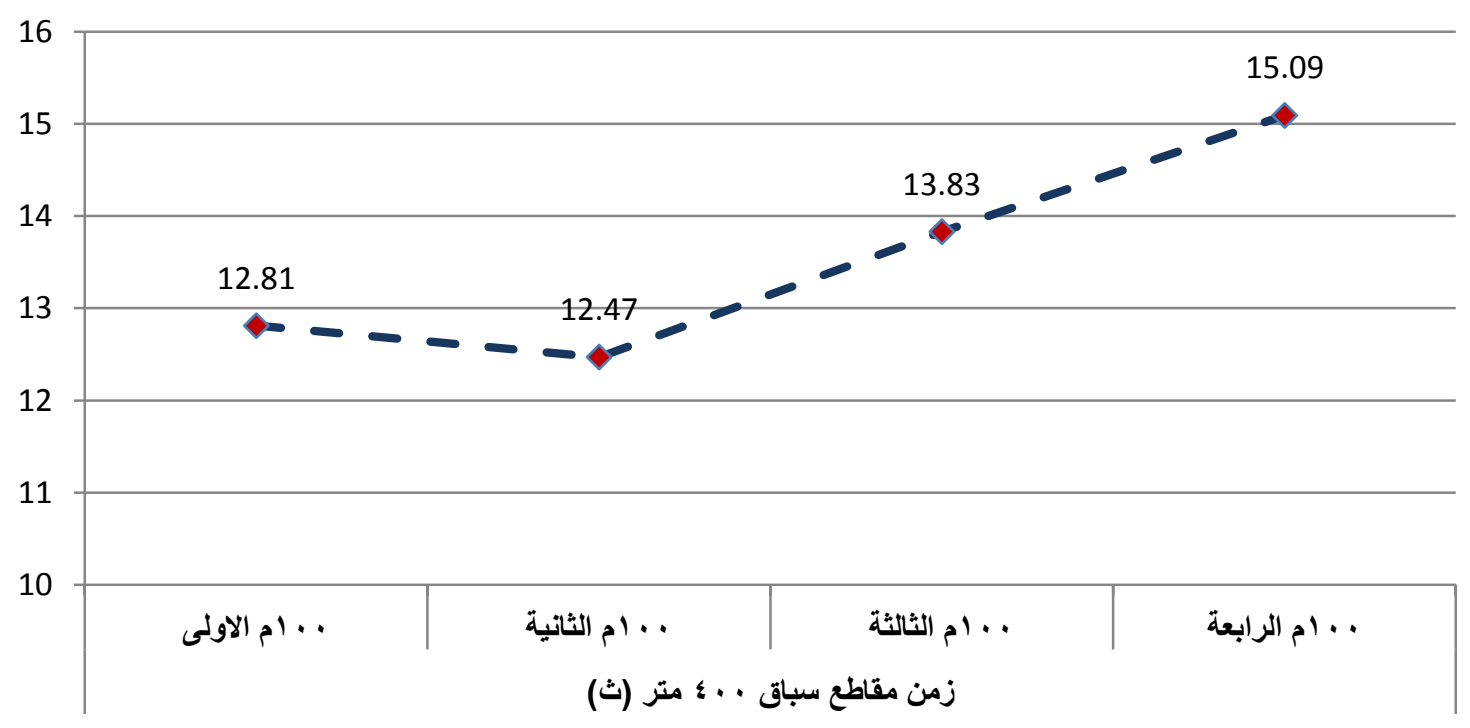

شكل (؛ ) المتوسط الحسابى فى زمن مقاطع سباق . . ؛ متر 
جدول (ء) التوصيف الإحصائي فى القياسات البيوميكانيكية لخطوة الجرى خلال . . 1 م الأولى فى سباق . ؛ متر $(9=0)$

\begin{tabular}{|c|c|c|c|c|c|c|c|c|}
\hline التفرطح & الالتواء & الانحراف المعيارى & المستوسط & قيمةً & قَيمة & \multicolumn{3}{|c|}{ المتغيرات } \\
\hline$\cdot, \mathrm{V} \vee \Lambda_{-}$ & $\cdot, Y 09$ &., .09 & r,I & T,YT & T,.0 & \multicolumn{2}{|c|}{ طول الخطوة } & \multirow{9}{*}{ الخطوة } \\
\hline$\cdot, \mathrm{V} \mathrm{HO}_{\mathrm{O}}$ & $1, \pi r$. & $\cdot, \cdots 9$ & $\cdot, \cdot \varepsilon$ & $\cdot, \cdot 7$ & $\cdot, \cdot \varepsilon$ & زمن الفرملة & \multirow{3}{*}{ زمن الارتكاز } & \\
\hline $1, V) \leqslant-$ & $\cdot, \wedge \circ V_{-}$ & $\cdot, \cdot 1 \cdot$ & $\cdot, \cdot V$ & $\cdot,+1$ & $\cdot, \cdot 7$ & زمن الدفع & & \\
\hline $1, \cdot \leq 1-$ & $\cdot, Y 17$ & $\cdot, .17$ & $\cdot, 1 Y$ & $\cdot, 1 \leq$ & $\cdot, 1$ & المجموع & & \\
\hline Y,OYI- & $\cdot, Y \vee I$ & $\cdot, .11$ &., 10 &., 17 & $\cdot, 1 \leq$ & \multicolumn{2}{|c|}{ زمن الطير ان } & \\
\hline $1,09 V_{-}$ & $\cdot, \cdot \vee O_{-}$ & $\varepsilon, 1 \ldots$ & 170,11 & $1 V \cdot, 70$ & 109,10 & \multicolumn{2}{|c|}{ زاوية الركبة الخلفية لحظة الدفع } & \\
\hline $0, \leqslant \leqslant Y$ & Y,17T_ & $r \leqslant, 001$ & $7 \wedge, Y 7$ & $9 \cdot, \varepsilon$ & $\Lambda$ & \multicolumn{2}{|c|}{ زاوية الركبة الامامية لحظة الدفع } & \\
\hline $1, \varepsilon \wedge \nearrow_{-}$ & $\cdot, 10 T_{-}$ & $\cdot, \cdot Y r$ & $\cdot, Y V$ & $\cdot, r$ & $\cdot, Y \leq$ & \multicolumn{2}{|c|}{ زمن الخطوة } & \\
\hline$r, \cdot 11-$ & $\cdot, r \leqslant V$ & $\cdot, 771$ & $\Lambda, \cdot \Lambda$ & $\Lambda, 97$ & 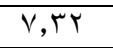 & \multicolumn{2}{|c|}{ سر عة الخطوة } & \\
\hline $1, \varepsilon 11-$ & $\cdot, \cdot r \theta_{-}$ & $\cdot, \cdot v \cdot$ & Y,IV & $r, Y V$ & $r, \cdot V$ & \multicolumn{2}{|c|}{ طول الخطوة } & \multirow{9}{*}{ الثانية } \\
\hline Y,OYI_ & $\cdot, Y \vee 1-$ & $\cdot, .11$ &., .0 & $\cdot, \cdot 7$ & $\cdot, \cdot \varepsilon$ & زمن الفرملة & \multirow{3}{*}{ زمن الارتكاز } & \\
\hline$\cdot, \mathrm{V} r \mathrm{O}$ & $1,7 Y \cdot-$ & $\cdot, \cdots 9$ & $\cdot, \cdot 1$ & $\cdot, \cdot \wedge$ & $\cdot, \cdot 7$ & زمن الدفع & & \\
\hline $1, \cdot \times q_{-}$ & $\cdot, \wedge Y O_{-}$ &., $.1 \mathrm{~V}$ & $\cdot, 14$ & $\cdot, 1 \leq$ & $\cdot, 1$ & المجموع & & \\
\hline $1, V) \leqslant-$ & $\cdot, \wedge \circ V_{-}$ & $\cdot, \cdot 1 \cdot$ & $\cdot, 10$ &., 17 & $\cdot, 1 \leq$ & \multicolumn{2}{|c|}{ زمن الطير ان } & \\
\hline $1,0 Y \varepsilon_{-}$ & •,YYT_ & Y,MIs & 171,94 & $17 \varepsilon, \wedge V$ & 101,0 & \multicolumn{2}{|c|}{ زاوية الركبة الخلفية لحظة الدفع } & \\
\hline $0, \wedge \leq 7$ & $Y, Y q \leq-$ & 9,00 & $\Lambda \cdot, \vee \Gamma$ & $\wedge \wedge, \varepsilon \leqslant$ & OV & \multicolumn{2}{|c|}{ زاوية الركبة الامامية لحظة الدفع } & \\
\hline $1, r \leqslant \Lambda_{-}$ & $\cdot$, ,ATr- & $\cdot, \cdot, r 7$ & $\cdot, \mathrm{YA}$ & $\cdot, r$ & $\cdot, Y \leq$ & \multicolumn{2}{|c|}{ زمن الخطوة } & \\
\hline $1,0 \cdot Y_{-}$ & $\cdot, \varepsilon \leqslant 1$ & $\cdot, V \backslash \pi$ & $\checkmark, \wedge Y$ & $\wedge, \vee q$ & 7,9 & \multicolumn{2}{|c|}{ سرعة الخطوة } & \\
\hline $1, Y 9 \varepsilon_{-}$ & $\cdot, \cdot 1 \mathrm{~V}$ & r,rqA & $\Sigma \vee, 0$ & 01 & $\varepsilon \varepsilon$ & \multicolumn{3}{|c|}{ عدد الخطو ات (عدد) } \\
\hline$\cdot, \leq \leqslant 7-$ & •, & $\cdot, Y \cdot \Sigma$ & $\vee, \wedge 1$ & $\Lambda, 19$ & $v, 09$ & \multicolumn{3}{|c|}{ متوسط السر عة (م/ث) } \\
\hline$\cdot, \wedge \backslash Y_{-}$ & $\cdot, \leqslant Y$. & $\cdot, Y \backslash M$ & $r, v 1$ & $\varepsilon, .0$ & $r, \S 1$ & \multicolumn{3}{|c|}{ متوسط التردد (خ/ث) } \\
\hline $1, Y 7 \varepsilon_{-}$ & $\cdot, 1 \cdot 1$ & $\cdot, 1 \cdot V$ & $r, 11$ & $r, r V$ & 1,97 & \multicolumn{3}{|c|}{ متوسط طول الخطوة (م) } \\
\hline$\cdot, 7 Y 9_{-}$ &., $0 \wedge 7_{-}$ & • & $|r, \Lambda|$ & $1 \%, 11$ & $|Y, Y|$ & \multicolumn{3}{|c|}{ زمن المقطع (ث) } \\
\hline
\end{tabular}

جدول (0) التوصيف الإحصائي فى القياسات البيوميكانيكية لخطوة الجرى خلال . . 1 م الثانية فى سباق . ـ متر $(9=\dot{0})$

\begin{tabular}{|c|c|c|c|c|c|c|c|c|}
\hline التفرطح & الالتواء & الالتحراف & المسابى & قيمةً & قيمة & \multicolumn{3}{|c|}{ المتغيرات } \\
\hline $1, \Gamma, \Lambda_{-}$ & $\cdot, \cdot+\cdot$ & $\cdot, .9 \leq$ & $r, 11$ & r,Yo & 1,91 & \multicolumn{2}{|c|}{ طول الخطوة } & \multirow{9}{*}{ الاولى } \\
\hline $1, V) \leq-$ & $\cdot, \wedge \circ \mathrm{V}$ & $\cdot, \cdot 1 \cdot$ & $\cdot, .0$ & $\cdot, \cdot 7$ & $\cdot, \cdot \varepsilon$ & زمن الفرملة & \multirow{3}{*}{ زمن الارتكاز } & \\
\hline$r, O Y_{1}-$ & $\cdot, Y V I_{-}$ & $\cdot, \cdot 11$ & $\cdot, \cdot 9$ & $\cdot, 1$ & $\cdot, \cdot \wedge$ & زمن الدفع & & \\
\hline$r, \cdot 1 \Lambda_{-}$ & 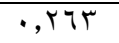 &., .19 &., $1 \leq$ &., 17 &., 14 & المجموع & & \\
\hline $1,1 \times 7$ & $\cdot, \cdot 11$ &.,$\cdot 1 Y$ & $\cdot, 1 \leq$ & $\cdot, 17$ & $\cdot, 14$ & \multicolumn{2}{|c|}{ زمن الطيران } & \\
\hline $1, \Gamma_{-}$ & $\cdot, \cdot q_{-}$ & $r,|r|$ & $17 \varepsilon, Y \leq$ & 171,70 & $109, \wedge \varepsilon$ & \multicolumn{2}{|c|}{ زاوية الركبة الخلفية لحظة الدفع } & \\
\hline$\cdot, Y \backslash Y$ & $1, .0 Y_{-}$ & $\Lambda, \vee 9$ & $\vee \wedge, \cdot \wedge$ & $\Lambda V, r Y$ & $71, Y_{0}$ & \multicolumn{2}{|c|}{ زاوية الركبة الامامية لحظة الدفع } & \\
\hline$\cdot, \wedge \cdots$ & $\cdot, 79 \cdot-$ & $\cdot, \cdot Y Y$ & $\cdot, \mathrm{rA}$ & $\cdot, r$ & $\cdot, Y \leq$ & \multicolumn{2}{|c|}{ زمن الخطوة } & \\
\hline$\cdot, 9 \wedge \Lambda_{-}$ & $\cdot, 1 \leqslant$ & $\cdot, V Y T$ & $v, 09$ & $\Lambda, \vee \backslash$ & 7,7 & \multicolumn{2}{|c|}{ سرعة الخطوة } & \\
\hline $1, r \cdot 9-$ & $\cdot, \cdot \wedge 1-$ & $\cdot, \cdot \vee \vee 9$ & $r, .9$ & T,Y & $1,9 V$ & \multicolumn{2}{|c|}{ طول الخطوة } & \multirow{9}{*}{ الخانية } \\
\hline $1, V \backslash \varepsilon_{-}$ & $\cdot, \wedge \circ \mathrm{V}$ & $\cdot, \cdot 1 \cdot$ & $\cdot, .0$ & $\cdot, \cdot 7$ & $\cdot, \cdot \varepsilon$ & زمن الفرملة & \multirow{3}{*}{ زمن الارتكاز } & \\
\hline $1, \cdot \sqrt{1} 9_{-}$ & $\cdot, \wedge Y O_{-}$ & $\cdot, \cdot 1 \mathrm{~V}$ & $\cdot, \cdot 9$ & $\cdot, 1$ & $\cdot, \cdot 7$ & زمن الدفع & & \\
\hline 1,007 & •, & $\cdot, \cdot Y \leq$ &., $1 \pi$ & $\cdot, 17$ & $\cdot, 1$ & المجموع & & \\
\hline $1, \vee \backslash \varepsilon_{-}$ & $\cdot, \wedge \circ \mathrm{V}$ & $\cdot, \cdot 1 \cdot$ &., 10 & $\cdot, 17$ & $\cdot, 1 \leq$ & \multicolumn{2}{|c|}{ زمن الطيران } & \\
\hline $1, \cdot 71-$ & $\cdot, r \cdot I$ & $r, \cdot \leq 0$ & ITr,9r & $171, Y_{0}$ & $109,1 \mathrm{~V}$ & \multicolumn{2}{|c|}{ زاوية الركبة الخلفية لحظة الدفع } & \\
\hline $1,17 \%$ & $\cdot, 1 \cdot r_{-}$ & $11,91 \leq$ & $V 7, Y \leq$ & $94, Y 4$ & $0 \wedge, Y 4$ & \multicolumn{2}{|c|}{ زاوية الركبة الامامية لحظة الدفع } & \\
\hline$\cdot, \wedge \cdots$ & $\cdot, 79 \cdot-$ & $\cdot, \cdot Y Y$ & $\cdot, \mathrm{r} \wedge$ & $\cdot, r$ & $\cdot, Y \leq$ & \multicolumn{2}{|c|}{ زمن الخطوة } & \\
\hline$\cdot, \wedge 99$ & $\cdot, .10$ & $\cdot, 771$ & $V, \leqslant 9$ & $\Lambda, 0 \leqslant$ & $7,0 \mathrm{~V}$ & \multicolumn{2}{|c|}{ سر عة الخطوة } & \\
\hline$\cdot, \wedge Y O_{-}$ & $\cdot, \cdot \leqslant 1$ & r,YVA & $\leqslant \varepsilon, \cdots$ & $\sum \vee, 0$ & $\varepsilon \cdot, 0$ & \multicolumn{3}{|c|}{ عدد الخطو ات (عدد) } \\
\hline$\cdot, Y T \varepsilon_{-}$ & $\cdot, \leqslant \vee 0_{-}$ & $\cdot, r 10$ & $\Lambda, \cdot r$ & $\Lambda, \leqslant 9$ & $v, 01$ & \multicolumn{3}{|c|}{ متوسط السر عة (م/ث) } \\
\hline$\cdot, 0 Y 1-$ & $\cdot, \mathrm{V} \wedge \wedge$ & $\cdot, Y M$ & $r, 0 r$ & $\Gamma, \wedge V$ & $r, r q$ & \multicolumn{3}{|c|}{ متوسط التردد (خ/ث) } \\
\hline 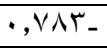 & • & $\cdot, 111$ & $r, r \wedge$ & $Y, \Sigma V$ & $r, 11$ & \multicolumn{3}{|c|}{ متوسط طول الخطوة (م) } \\
\hline$\cdot, 1 \vee 7_{-}$ & $\cdot, T Y Y$ & $\cdot, \leqslant 9 \wedge$ & $1 Y, \Sigma V$ & $1 \mu, \mu$ & $11, \times \wedge$ & \multicolumn{3}{|c|}{ زمن المقطع (ث) } \\
\hline
\end{tabular}


جدول (†) التوصيف الإحصائي فى القياسات البيوميكانيكية لخطوة الجرى خلال . 1 م الثالثة فى سباق . ؛ متر $(9=0)$

\begin{tabular}{|c|c|c|c|c|c|c|c|c|}
\hline التفرطح & الالتواء معامل & الانعريارى اف & المتوسط الحسي & قيمة & قُقة & \multicolumn{3}{|c|}{ المتغيرات } \\
\hline 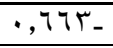 & $\cdot, 0 \wedge V_{-}$ & $\cdot, 1 Y \leq$ & $r, .0$ & T,YY & $1, \wedge \Sigma$ & \multicolumn{2}{|c|}{ طول الخطوة } & \multirow{9}{*}{ الخطوة } \\
\hline $1, V 1 \varepsilon_{-}$ & $\cdot, \wedge \circ V_{-}$ & $\cdot, \cdot 1 \cdot$ & $\cdot, .0$ & $\cdot, \cdot 7$ & $\cdot, \cdot \varepsilon$ & زمن الفرملة & \multirow{3}{*}{ زمن الارتكاز } & \\
\hline$\cdot$, , \^ & $\cdot, 7 \cdot 7$ & $\cdot, \cdot 1 \leq$ & $\cdot, .9$ &., 14 & $\cdot, \cdot \wedge$ & زمن الدفع & & \\
\hline$\cdot, T \leqslant r_{-}$ & $\cdot, 1 \cdot V$ & $\cdot, \cdot T \cdot$ & $\cdot, 10$ & $\cdot, 11$ & $\cdot, 1 Y$ & المجموع & & \\
\hline$\cdot, \cdot \leq \cdot-$ & $\cdot, r \circ \varepsilon_{-}$ & $\cdot, .1 T$ & $\cdot, 17$ & $\cdot, 11$ & $\cdot, 1 \leq$ & \multicolumn{2}{|c|}{ زمن الطيران } & \\
\hline 1,791 & $\cdot, \cdot T \leq$ & $r, \wedge \vee V$ & $17 \leqslant, Y 0$ & $179, V$ & 109,10 & \multicolumn{2}{|c|}{ زاوية الركبة الخلفية لحظة الدفع } & \\
\hline$\cdot, I \vee V_{-}$ & $\cdot, \cdot T \varepsilon$ & $I T, Y V V$ & $V V, V Y$ & 99 & $00, \leqslant \leqslant$ & \multicolumn{2}{|c|}{ زاوية الركبة الامامية لحظة الدفع } & \\
\hline 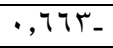 & $\cdot, \cdot 1 \cdot-$ & $\cdot, \cdot r r$ & $\cdot, r)$ & $\cdot, \mathrm{MT}$ & $\cdot, Y_{T}$ & \multicolumn{2}{|c|}{ زمن الخطوة } & \\
\hline$\cdot, r \mid \Lambda$ & $\cdot, 7.0$ & $\cdot, 9 \wedge r$ & 7,71 & $\Lambda, 0 \leqslant$ & $0, \mu$ & \multicolumn{2}{|c|}{ سر عة الخطوة } & \\
\hline$\cdot, \leqslant \curlyvee \cdot-$ & $\cdot, \wedge \vee V_{-}$ & $\cdot, 11 \cdot$ & $r, \cdot V$ & $r, 19$ & $1, \wedge \mathrm{V}$ & \multicolumn{2}{|c|}{ طول الخطوة } & \multirow{9}{*}{ الخطانية } \\
\hline $1, V 1 \varepsilon_{-}$ & $\cdot, \wedge \circ V_{-}$ & $\cdot, \cdot 1 \cdot$ & $\cdot, .0$ &., .7 & $\cdot, \cdot \varepsilon$ & زمن الفرملة & \multirow{3}{*}{ زمن الارتكاز } & \\
\hline., 110 & $1, \cdot 1 \varepsilon$ &., .10 & $\cdot, .9$ & $\cdot, 14$ & $\cdot, \cdot 1$ & زمن الدفع & & \\
\hline$\cdot, \ldots 9$ & $\cdot, 0 \cdot r$ & $\cdot, .19$ & $\cdot, 1 \leq$ &., 11 & $\cdot, 14$ & المجموع ال الموع & & \\
\hline $1, \times 1 \varepsilon_{-}$ & $\cdot, \wedge \circ V_{-}$ & $\cdot, \cdot 1 \cdot$ & $\cdot, 10$ &., 17 & $\cdot, 1 \leq$ & \multicolumn{2}{|c|}{ زمن الطير ان } & \\
\hline$\cdot, 079$ & $\cdot, 07 \pi$ & $r, 90 \wedge$ & $17 \leqslant, \leqslant 7$ & 179,1 & $171, r$ & \multicolumn{2}{|c|}{ زاوية الركبة الخلفية لحظة الدفع } & \\
\hline., $1 \times 0$ & $\cdot, \backslash \wedge \varepsilon_{-}$ & $M, 114$ & $V T, r u$ & $9 \cdot, 01$ & $01, \sum T$ & \multicolumn{2}{|c|}{ زاوية الركبة الامامية لحظة الدفع } & \\
\hline$\cdot, \wedge \cdot \Lambda_{-}$ & $\cdot, \wedge \vee 0$ & 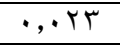 & $\cdot, r \cdot$ & $\cdot, \Gamma \leqslant$ & $\cdot, r \wedge$ & \multicolumn{2}{|c|}{ زمن الخطوة } & \\
\hline 1,Yצח- & $\cdot, 0 V T_{-}$ & $\cdot, 79 V$ & $\mathrm{~V}, \ldots$ & $\vee, 7 \wedge$ & $0, \wedge \wedge$ & \multicolumn{2}{|c|}{ سرعة الخطوة } & \\
\hline 1,זי- & $\cdot, \Pi ו$ & $r, \ldots$ & $\sum \neg, \wedge r$ & 01 & $\varepsilon r$ & \multicolumn{3}{|c|}{ عدد الخطوات (عدد) } \\
\hline $1, \leq 71$ & $\cdot, Y T \leq-$ & $\cdot, r q$. & $V, r \leq$ & $\mathrm{V}, \mathrm{VO}$ & 7,79 & \multicolumn{3}{|c|}{ متوسط السرعة (م/ث) } \\
\hline $1, r V \varepsilon_{-}$ & $\cdot, 094$ & $\cdot, 1 \wedge \mathrm{V}$ & $r, r q$ & $r, T \wedge$ & $r, I V$ & \multicolumn{3}{|c|}{ متوسط التردد (خ/ث) } \\
\hline 1,£।・- & $\cdot, I V Y_{-}$ & $\cdot, 1 \% 4$ & $r, I \leq$ & r,ru & 1,97 & \multicolumn{3}{|c|}{ منوسط طول الخطوة (م) } \\
\hline $1, T V Y$ & $\cdot, 0 Y 7$ & $\cdot, 07$. & $1 \Gamma, \wedge r$ & $1 \leq, 9 \leq$ & $\mid r, q 1$ & \multicolumn{3}{|c|}{ زمن المقطع (ث) } \\
\hline
\end{tabular}

جدول (V) التوصيف الإحصائي فى القياسات البيوميكانيكية لخطوة الجرى خلال . 1 م الرابعة فى سباق . ع متر $(9=0)$

\begin{tabular}{|c|c|c|c|c|c|c|c|c|}
\hline التفرطح معامل & الالتواء & الالمعرافيارى & المستوسطى & قأعلي & قَيمة & \multicolumn{3}{|c|}{ المتغيرات } \\
\hline $1, \cdot V r_{-}$ & $\cdot, 10 Y_{-}$ & $\cdot, 101$ & $1, \wedge \vee$ & T,1 & 1,7r & \multicolumn{2}{|c|}{ طول الخطوة } & \multirow{9}{*}{ الاولى الخطوة } \\
\hline $1, V 1 \varepsilon_{-}$ & $\cdot, \wedge \circ \mathrm{V}$ & $\cdot, \cdot 1 \cdot$ & $\cdot, \cdot V$ & $\cdot, \cdot \wedge$ & $\cdot, \cdot 7$ & زمن الفرملة & \multirow{3}{*}{ من الارتكاز } & \\
\hline $1, \cdot \leq 1-$ & $\cdot, Y \backslash Y_{-}$ & $\cdot, .17$ & $\cdot, 1$ & $\cdot, 1 r$ & $\cdot, \cdot \wedge$ & زمن الدفع & & \\
\hline $1,1 \times 1-$ & $\cdot, 1 \vee 4$ & .,.,YT & $\cdot, \mathrm{IV}$ & $\cdot, Y$ & $\cdot, 1 \leq$ & المجموع & & \\
\hline$\cdot, Y \wedge T_{-}$ & $\cdot, 7 \cdot 7$ & $\cdot, \cdot 1 \leq$ &., 10 & $\cdot, 1 \wedge$ & $\cdot, 1 \leq$ & \multicolumn{2}{|c|}{ زمن الطيران } & \\
\hline • & $1, \cdot 1 \cdot-$ & $0,07 \varepsilon$ & ITr,^A & 179 & IOT,Y & \multicolumn{2}{|c|}{ زاوية الركبة الخلفية لحظة الدفع } & \\
\hline$\cdot, 7 \mu V_{-}$ & $\cdot, \vee \vee \leqslant \varepsilon_{-}$ & 11,1 ro & $\vee \wedge, 91$ & $9 Y, \xi$ & $T \cdot, \wedge V$ & \multicolumn{2}{|c|}{ زاوية الركبة الامامية لحظة الدفع } & \\
\hline$\cdot$, ro.- & $\cdot, T \wedge V$ & ., & 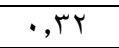 & $\cdot, \Gamma \wedge$ & $\cdot, r \wedge$ & \multicolumn{2}{|c|}{ زمن الخطوة } & \\
\hline $1, I V V_{-}$ & $\cdot, .09$ & $\cdot, \vee \vee 09$ & $0, \wedge 7$ & V & $\varepsilon, \vee q$ & \multicolumn{2}{|c|}{ سر عة الخطوة } & \\
\hline $1, \leq \leqslant 9-$ & $\cdot, \cdots r_{-}$ & $\cdot, Y \backslash \leq$ & $1, \wedge \wedge$ & Y,IV & 1,71 & \multicolumn{2}{|c|}{ طول الخطوة } & \multirow{9}{*}{ الثانية } \\
\hline$\cdot, \mathrm{V} r \mathrm{O}$ & $1,7 Y$. & $\cdot, \cdots 9$ & $\cdot, \cdot 9$ & $\cdot, \cdot \wedge$ & $\cdot, \cdot 7$ & زمن الفرملة & \multirow{3}{*}{ زمن الارتكاز } & \\
\hline $1, \cdot \leq 1-$ & $\cdot, Y \backslash 7$ & $\cdot, .17$ & $\cdot, 1$ & $\cdot, I T$ & $\cdot, \cdot \wedge$ & زمن الدفع & & \\
\hline$\cdot, Y Y q_{-}$ & $\cdot, 9 \leq V$ & $\cdot, \cdot Y T$ &., 17 & $\cdot, r$ & $\cdot, 1 \leq$ & المجموع & & \\
\hline$\cdot, \cdot \leq \cdot-$ & $\cdot, Y \circ \leq$ & $\cdot, \cdot 1 T$ & $\cdot, 17$ & $\cdot, 1 \wedge$ & $\cdot, 1 \leq$ & \multicolumn{2}{|c|}{ زمن الطير ان } & \\
\hline$\cdot, 7 \cdots$ & $\cdot, \leqslant \vee \nearrow_{-}$ & $0, Y M \cdot$ & 171,19 & $179, Y$ & 10r & \multicolumn{2}{|c|}{ زاوية الركبة الخلفية لحظة الدفع } & \\
\hline $1, r_{H} r_{-}$ & $\cdot, 117_{-}$ & $M, r \leqslant 9$ & $\Lambda Y, r \varepsilon$ & $99, \cdot 1$ & 70 & \multicolumn{2}{|c|}{ زاوية الركبة الامامية لحظة الدفع } & \\
\hline$\cdot, \cdot 1 \wedge$ & $\cdot, \wedge \backslash \wedge$ & $\cdot, \cdot \Gamma \leqslant$ & $\cdot, r$ r & $\cdot, \Gamma \wedge$ & $\cdot, r \wedge$ & \multicolumn{2}{|c|}{ زمن الخطوة } & \\
\hline$\cdot, 07 \varepsilon_{-}$ & $\cdot, \cdots V_{-}$ & $\cdot, \vee \vee 94$ & $0,9 V$ & $\mathrm{~V}, \mathrm{IV}$ & $\varepsilon, \vee 0$ & \multicolumn{2}{|c|}{ سر عة الخطوة } & \\
\hline $1, r \leq \Lambda_{-}$ & $\cdot, \varepsilon \Gamma \uparrow$ & $r, 791$ & $\sum 9,7 \vee$ & 00,0 & $\leqslant 0$ & \multicolumn{3}{|c|}{ عدد الخطو ات (عدد) } \\
\hline$\cdot, \Lambda \cdot Y_{-}$ & $\cdot, 1 \vee 0_{-}$ & $\cdot, \leqslant Y \uparrow$ & 7,70 & $V, Y Y$ & 0,97 & \multicolumn{3}{|c|}{ متوسط السر عة (م/ث) } \\
\hline $1, \wedge Y O_{-}$ & $\cdot, \leqslant 9 \leqslant$ & $\cdot, 1 \Gamma \leq$ & $r, r q$ & $r, \leqslant q$ & $r, 10$ & \multicolumn{3}{|c|}{ متوسط التردد (خ/ث) } \\
\hline $1, \Gamma \cdot 0_{-}$ & $\cdot, r \vee O_{-}$ & $\cdot, 1 \leq V$ & $Y, \cdot Y$ & Y,YY & $1, \wedge$. & \multicolumn{3}{|c|}{ متوسط طول الخطوة (م) } \\
\hline$\cdot, 0 \wedge \varepsilon_{-}$ & $\cdot, r q 1$ & $\cdot, 9 \wedge 1$ & $10, .9$ & $17, \vee \wedge$ & $I T, V \wedge$ & \multicolumn{3}{|c|}{ زمن المقطع (ث) } \\
\hline
\end{tabular}


جدول (^) معاملات الإرتباط بين المتغيرات البيوميكانيكية لخطوة الجرى وتغيرات الإنزيمات واللاكتيك خلال سباق (...

\begin{tabular}{|c|c|c|c|c|c|}
\hline تركيز حامض اللاكتيك & لاكتيك ديهيل انزيم & 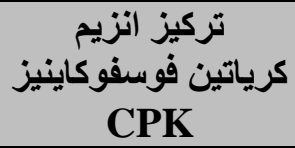 & \multicolumn{3}{|c|}{ المتغيرات } \\
\hline$* * ., 011-$ & $\cdot, 1 \wedge 9_{-}$ & $* * ., \leqslant \leqslant \Gamma_{-}$ & \multicolumn{2}{|c|}{ طول الخطوة } & \multirow{9}{*}{ الاولى } \\
\hline$* * ., 079$ & $\cdot, I \vee \wedge$ & $\star * \cdot, \leq \leqslant 0$ & زمن الفرملة & \multirow{3}{*}{ زمن الارتكاز } & \\
\hline$* *,, 7 \ldots$ & $\cdot, 101$ & $* * ., 07 \Lambda$ & زمن الدفع & & \\
\hline$* *,, 7 \leqslant \Lambda$ & $\cdot, 110$ & $* * ., 07 \mathrm{~V}$ & المجموع & & \\
\hline$*,, r \wedge q$ & 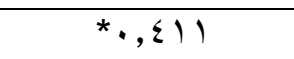 & *., & \multicolumn{2}{|c|}{ زمن الطيران } & \\
\hline$\cdot, 110_{-}$ & $\cdot, 1 \wedge Y$ & $\cdot, \cdot 1 \mu$ & \multicolumn{2}{|c|}{ زاوية الركبة الخلفية لحظة الدفع } & \\
\hline$\cdot, Y Y Y$ & *, ror & $\cdot, Y Y q$ & \multicolumn{2}{|c|}{ زاوية الركبة الامامية لحظة الدفع } & \\
\hline$* * \cdot, 7 \leq 9$ & $\cdot, \mu$ & $* * ., 07 \varepsilon$ & \multicolumn{2}{|c|}{ زمن الخطوة } & \\
\hline${ }^{* *} \cdot, 79 \leq-$ & $\cdot, r Y q_{-}$ & $* * ., 0 \vee 9_{-}$ & \multicolumn{2}{|c|}{ سر عة الخطوة } & \\
\hline${ }^{* *} \cdot, \leqslant \vee{ }_{-}$ &., $10 \leqslant-$ & $* *,, \leqslant \circ V_{-}$ & \multicolumn{2}{|c|}{ طول الخطوة } & \multirow{9}{*}{ الخانية } \\
\hline$*_{\cdot,, r \vee q}$ & $\cdot, \cdots \Lambda_{-}$ & $\cdot, \Gamma \cdot I$ & زمن الفرملة & \multirow{3}{*}{ ز - من الارتكاز } & \\
\hline$* * \cdot, \leqslant 99$ & $\cdot, Y \backslash I$ & $* * \cdot, \Sigma \Gamma V$ & زمن الدفع & & \\
\hline$* *,, 0, \varepsilon$ & $\cdot, 1 \Gamma \varepsilon$ & $* * \cdot, \Sigma Y V$ & المجموع & & \\
\hline$\cdot, 11 \mathrm{~V}$ & $\cdot, 11 \mathrm{~V}$ & $\cdot, \cdot 7 \Lambda_{-}$ & \multicolumn{2}{|c|}{ زمن الطيران } & \\
\hline ( & *, rᄉI & $\cdot, 11 \mathrm{~V}$ & \multicolumn{2}{|c|}{ زاوية الركبة الخلفية لحظة الدفع } & \\
\hline$\cdot, 117$ & $\cdot, 11 \mathrm{~V}$ & $\cdot, \cdot 70_{-}$ & \multicolumn{2}{|c|}{ زاوية الركبة الامامية لحظة الدفع } & \\
\hline$* * ., \leqslant 0 r$ & $\cdot, 104$ & •, & \multicolumn{2}{|c|}{ زمن الخطوة } & \\
\hline${ }^{* *} \cdot, 099-$ & $\cdot, r \backslash \Lambda_{-}$ & $* * \cdot,\{\neg \wedge$ & \multicolumn{2}{|c|}{ سر عة الخطوة } & \\
\hline$\cdot, Y \backslash 7$ & $\cdot, \cdot 17$ & $* *,, \Sigma \leqslant Y$ & \multicolumn{3}{|c|}{ عدد الخطو ات (عدد) } \\
\hline${ }^{* *} \cdot$, , Vฯー & $\cdot, Y q \varepsilon_{-}$ & **.,รไ7- & \multicolumn{3}{|c|}{ متوسط السر عة (م/ث) } \\
\hline${ }^{* *} \cdot, 719-$ & *., rq & $\cdot, 1 \leq 1-$ & \multicolumn{3}{|c|}{ متوسط التردد (خ/ث) } \\
\hline$\cdot, r \cdot V_{-}$ &., $0 \leqslant$ & $\left.*_{*}, \leqslant\right) q_{-}$ & \multicolumn{3}{|c|}{ منوسط طول الخطوة (م) } \\
\hline **.,77. & $\cdot, Y V V$ & **., $\Sigma \wedge Y$ & \multicolumn{3}{|c|}{ زمن الدقطع (ث) } \\
\hline
\end{tabular}

يتضح من جدول (^) والخاص بمعاملات الإرتباط بين متغيرات الخطوة الأولى والثانية والمتغيرات

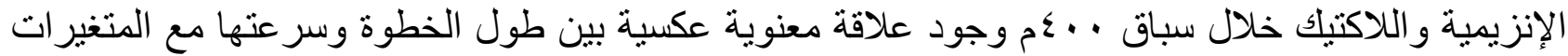

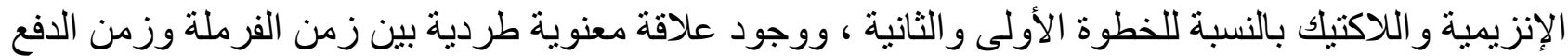

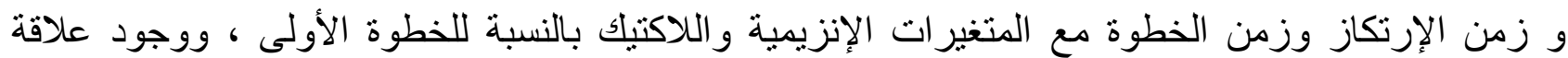
معنوية طردية بين زمن الفرملة وزمن الدفع وزمن الإرتكاز وكذللك زمن الخطوة مع إنزيم كرياتين فسفوكينيز

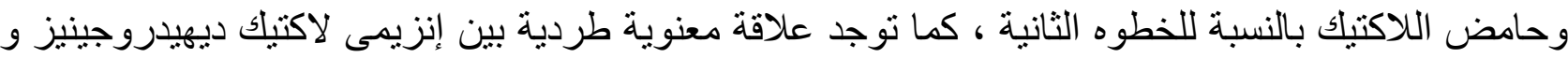
فسفوكينيز وحامض اللاكتيك . 
جدول (9) تحليل التباين فى المتغيرات البيوميكانيكية للخطوة الجرى بين مقاطع سباق ، . ؛ متر

\begin{tabular}{|c|c|c|c|c|c|c|c|}
\hline قالمحسوبة "فية & متوسط المربعات & الحرجية & المربعات & التباين & \multicolumn{3}{|c|}{ المتغيرات } \\
\hline \multirow{3}{*}{$* * q, \wedge \leq 0$} &., $1 \times 9$ & $\bar{\mu}$ & $\cdot, \Gamma \wedge \wedge$ & بين المجمو عات & \multirow{3}{*}{\multicolumn{2}{|c|}{ طول الخطوة }} & \multirow{27}{*}{ الاولى } \\
\hline & $\cdot, \cdot 1 \pi$ & Tr & $\cdot,\{Y ו$ & داخل المجمو عات & & & \\
\hline & & ro & $\cdot, \wedge \cdot 9$ & المجموع & & & \\
\hline \multirow{3}{*}{$* * q$, or } & $\cdot, \cdots 1$ & $r$ & $\cdot, \ldots r$ & بين المجمو عات & \multirow{3}{*}{ زمن الفرملة } & \multirow{9}{*}{ زمن الارتكاز } & \\
\hline &,$\cdots$ & Tr & $\cdot, \ldots r$ & داخل المجمو عات & & & \\
\hline & & ro & $\cdot, \ldots 7$ & المجموع & & & \\
\hline \multirow{3}{*}{$* * \wedge, .0$} & $\cdot, \cdots 1$ & $r$ & $\cdot, \ldots \leq$ & بين المجمو عات & \multirow{3}{*}{ زمن الدفع } & & \\
\hline & $\cdot, \cdots$ & Tr & $\cdot, \cdots 0$ & داخل المجمو عات & & & \\
\hline & & ro & $\cdot, \cdots 9$ & المجموع & & & \\
\hline \multirow{3}{*}{$* *) \cdot, \vee \wedge$} & $\cdot, \cdots \varepsilon$ & $r$ & $\cdot, \cdot 1 r$ & بين المجمو عات & \multirow{3}{*}{ المجموع } & & \\
\hline & $\cdot, \cdots$ & rt & $\cdot, \cdot 1 Y$ & داخل المجمو عات & & & \\
\hline & & ro & $\cdot, \cdot Y \leq$ & المجموع & & & \\
\hline \multirow{3}{*}{$* * \leqslant, 97$} & $\cdot, \cdots 1$ & $r$ & $\cdot, \cdots r$ & بين المجمو عات & \multirow{3}{*}{\multicolumn{2}{|c|}{ زمن الطيران }} & \\
\hline & $\cdot, \cdots$ & rT & $\cdot, \cdots 0$ & داخل المجمو عات & & & \\
\hline & & ro & $\cdot, \cdots v$ & المجموع & & & \\
\hline \multirow{3}{*}{$\cdot, \leqslant \Gamma$} & $\vee, \vee \vee O$ & $r$ & Tr,TrO & بين المجمو عات & \multirow{3}{*}{\multicolumn{2}{|c|}{ زاوية الركبة الخلفية لحظة الدفع }} & \\
\hline & $1 \wedge, 1 \% 4$ & rr & $O \Lambda \cdot, \Pi \mu \wedge$ & داخل المجمو عات & & & \\
\hline & & ro & צ. & المجموع & & & \\
\hline \multirow{3}{*}{$\cdot, 94$} & YYO,qTE & $r$ & $T \vee \vee, \wedge$. & بين المجمو عات & \multirow{3}{*}{\multicolumn{2}{|c|}{ زاوية الركبة الامامية لحظة الدفع }} & \\
\hline & $r \leqslant 0, .99$ & rt & $V \wedge \leq T, I V$ & داخل المجمو عات & & & \\
\hline & & ro & А०Y.,9^ & المجموع & & & \\
\hline & $\cdot, \cdots 7$ & $r$ & $\cdot, \cdot 11$ & بين المجموعات & & & \\
\hline$* * \vee, 9 \vee$ & $\cdot, \cdots 1$ & re & $\cdot, \cdot Y \leq$ & داخل المجمو عات & & 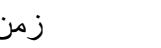 & \\
\hline & & ro & $\cdot, \cdot \leq \Gamma$ & المجموع & & & \\
\hline & А, & $r$ & Y0,917 & بين المجمو عات & & & \\
\hline$* * \mid r, \vee \wedge$ & $\cdot, T Y V$ & rY & $r \cdot, 00$ & داخل المجمو عات & 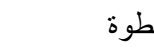 & 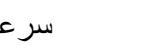 & \\
\hline & & ro & $\leqslant 0,9 \vee$. & المجموع & & & \\
\hline & 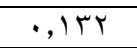 & $r$ & $\cdot, r 97$ & بين المجمو عات & & & \\
\hline$* * \vee, 74$ & $\cdot, \cdot 1 \mathrm{~V}$ & re & $\cdot, 000$ & داخل المجمو عات & & طول & \\
\hline & & ro & $\cdot, 901$ & المجموع & & & \\
\hline & $\cdot, \cdots 1$ & $r$ & $\cdot, \cdots r$ & بين المجمو عات & & & \\
\hline$* * 0, r$. & $\cdot, \cdots$ & rt & $\cdot, \ldots r$ & داخل المجمو عات & زمن الفرملة & & \\
\hline & & ro & $\cdot, \ldots 0$ & المجموع & & & \\
\hline & $\cdot, \cdots 1$ & $r$ & $\cdot, \ldots r$ & بين المجمو عات & & & \\
\hline * & $\cdot, \cdots$ & Tr & $\cdot, \cdots V$ & داخل المجمو عات & زمن الدفع & زمن الارتكاز & \\
\hline & & ro & $\cdot, \cdots 9$ & المجموع & & & \\
\hline & $\cdot, \cdots r$ & $r$ & $\cdot, \cdots V$ & بين المجمو عات & & & \\
\hline$* * \varepsilon, \vee \vee$ & $\cdot, \cdots$ & Tr & $\cdot, \cdot 10$ & داخل المجمو عات & المجموع & & \\
\hline & & ro & $\cdot, \cdot Y I$ & المجموع & & & \\
\hline & $\cdot, \cdots$ & $r$ & $\cdot, \cdots$ & بين المجمو عات & & & \\
\hline $1,1 r$ & $\cdot, \cdots$ & rT & $\cdot, \cdots \varepsilon$ & داخل المجمو عات & & ز زمن & الخثانبة \\
\hline & & ro & $\cdot, \cdots \varepsilon$ & المجموع & & & \\
\hline & $17, \cdot 1 \leq$ & $r$ & $\{\Lambda, \cdot \varepsilon$ & بين المجمو عات & & & \\
\hline 1,Y & IY,TAE & rY & $\varepsilon \cdot 0, \wedge \Lambda$ & داخل المجمو عات & ة لحظة الدفع & زاوية الركبة | & \\
\hline & & ro & हOr, १Y & المجموع & & & \\
\hline & 10Y,डाT & $r$ & $\Sigma O V, Y \leqslant$ & بين المجمو عات & & & \\
\hline 1,10 & Irr,q.. & Tr & $\varepsilon r \circ Y, V q$ & داخل المجمو عات & بة لحظة الدفع & زاوية الركبة ا & \\
\hline & & ro & $\varepsilon V \mid \cdot, \cdot r$ & المجموع & & & \\
\hline & $\cdot, \ldots r$ & $r$ & $\cdot, \cdots 9$ & بين المجمو عات & & & \\
\hline$* \varepsilon, \cdot \varepsilon$ &,,$\cdots 1$ & ry & $\cdot, \cdot T H$ & داخل المجمو عات & & زمن & \\
\hline & & ro & $\cdot, \cdot T r$ & المجموع & & & \\
\hline & $0, \wedge Y V$ & $r$ & $I V, \Sigma \Lambda Y$ & بين المجموعات & & & \\
\hline$* * 11, r q$ &., 017 & rY & 17,010 & داخل المجمو عات & 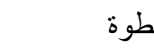 & سرع & \\
\hline & & ro & rr,q9V & المجموع & & & \\
\hline$* * 0, \wedge 7$ & $\varepsilon 9,17 V$ & $\mu$ & $1 \leqslant \vee, 0 \ldots$ & بين المجمو عات & & د الخطو ات (ع & \\
\hline
\end{tabular}




\begin{tabular}{|c|c|c|c|c|c|}
\hline "قيمة "فـ" & متوسط المربعات & الحرية & المربعات & التباين & المتغيرات \\
\hline & $\wedge, r q)$ & re & $r \curlyvee \wedge, 0 \ldots$ & داخل المجمو عات & \\
\hline & & ro & $\sum 17, \ldots$ & المجموع & \\
\hline \multirow{3}{*}{ **r, } & r,รTr & $r$ & $1 \cdot, r q$. & بين المجمو عات & \multirow{3}{*}{ متوسط السر عة (م/ث) } \\
\hline & $\cdot, 1 \cdot r$ & ru & $r, Y V V$ & داخل المجمو عات & \\
\hline & & ro & 1 ו & المجموع & \\
\hline \multirow{3}{*}{$* * \wedge, 0}$. & $\cdot, r \cdot r$ & $r$ & $\cdot, 9.9$ & بين المجمو عات & \multirow{3}{*}{ متوسط التردد (خ/ث) } \\
\hline & (1, & rt & $1,1 \leq$ & داخل المجمو عات & \\
\hline & & ro & $r, \cdot \leq q$ & المجموع & \\
\hline \multirow{3}{*}{ 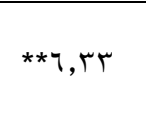 } & $\cdot, 1 \cdot r$ & $r$ & $\cdot, r \cdot \Lambda$ & بين المجمو عات & \multirow{3}{*}{ منوسط طول الخطوة (م) } \\
\hline & $\cdot, .17$ & rT &., 011 & داخل المجمو عات & \\
\hline & & ro & $\cdot, \wedge Y \tau$ & المجموع & \\
\hline \multirow{3}{*}{$* * \Gamma \cdot, V \vee$} & IT,071 & $r$ & $r V, V \cdot r$ & بين المجمو عات & \multirow{3}{*}{ زمن المقطع (ث) } \\
\hline & $\cdot, \varepsilon \cdot \Lambda$ & rt & $11, .79$ & داخل المجمو عات & \\
\hline & & ro & $0 ., V V Y$ & المجموع & \\
\hline \multirow{3}{*}{ *r,vq } & $1011 \cdot 1, r r$ & $r$ & EOTMY & بين المجمو عات & \multirow{3}{*}{ (u/l) CPK انزيم كرياتين فوسفوكاينيز } \\
\hline & rqATV,Or & rr & $T r V \leqslant \leqslant \Lambda \cdot, T V$ & داخل المجمو عات & \\
\hline & & ro & IVYVA.0,TE & المجموع & \\
\hline \multirow{3}{*}{$* * \leqslant, 97$} & $V 00 \cdot \varepsilon, V V$ & $r$ & 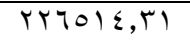 & بين المجمو عات & \multirow{3}{*}{ (u/l) LDH انزيم لاكتيك ديهيدروجينيز } \\
\hline & IOY.V,TV & $\begin{array}{ll}r \\
r\end{array}$ & 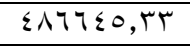 & داخل المجمو عات & \\
\hline & & ro & $V 1 T 109,7 \leq$ & 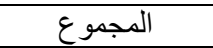 & \\
\hline \multirow{3}{*}{$* * 0$ r $\wedge, 00$} & TY.OY,r. & $r$ & 77107,19 & بين المجمو عات & \multirow{3}{*}{ تركيز حامض اللاكتيك (mg/l) } \\
\hline & $\Sigma 1, V Y$ & rt & $1 r r 0,11$ & داخل المجمو عات & \\
\hline & & ro & $T V \leq 9 Y$ & المجموع & \\
\hline
\end{tabular}

يتضـح مـن جـدول (9) و الخـاص بتحليـل التبـاين للمتغيـر ات البيوميكانيمكيـة للخطـوة و المتغيـر ات الإنزيميـة و اللاكتيك وتردد الخطوة خـلال مر احل سباق . عم وجود فروق معنويـة بين مر احل السباق فى المتغير ات بالنسبة للخطوة الأولى ( طول الخطوة _- زمن الفرملة - زمن الدفع - زمن الإرتكاز - زمن الطيران - زمن الخطوة ـ سـرعة الخطوة ) وبالنسـبة للخطـوة الثانيـة ( طـول الخطـوة - زمـن الفرملـة - زمـن الدفع - زمـن الإرتكاز - زمن الخطوة - سر عة الخطوة ) وبالنسبة لمتغير ات الخطوة خلال السباق (عدد الخطوات ـ متوسط

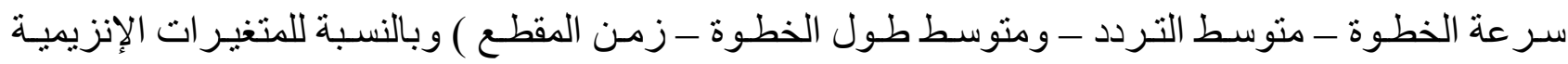
و اللاكتيك ( إنزيم كرياتين فسفوكينيز - إنزيم لاكتيك ديهيدرو جينيز - حامض اللاكتيك ) 
جدول ( • 1) أقل فرق معنوى لبنفرونى ونسبة الفرق فى المتغيرات البيوميكانيكية للخطوة الجرى بين مقاطع سباق . . ـ متر الفير

\begin{tabular}{|c|c|c|c|c|c|c|c|c|c|c|}
\hline \multicolumn{6}{|c|}{ فروق المتوسطات } & \multirow{3}{*}{ الحسابى } & \multirow{3}{*}{ السباق } & \multirow{3}{*}{\multicolumn{3}{|c|}{ المتغيرات }} \\
\hline \multicolumn{2}{|c|}{ · . أ م الرابعة } & \multicolumn{2}{|c|}{ ل . ام الثالثة } & \multicolumn{2}{|c|}{. . ام الثانية } & & & & & \\
\hline الفرقبة\% & الفرق & الفرقبة\% & القفرق & الفرقبة\% & الفرق & & & & & \\
\hline$\%$ \%Y,OY & ${ }^{*} \cdot, Y 7 \Lambda$ & $\% \leqslant, 10$ & $\cdot, \cdot 1 \wedge 9$ & $\% 1, \varepsilon$ & $\cdot, \cdot, r$. & $r, I \leqslant 1$ & ·. ام الاولى & \multirow{4}{*}{\multicolumn{2}{|c|}{ طول الخطوة }} & \multirow{36}{*}{ الاولىوة } \\
\hline$\%$ \%,rV & ${ }^{*} \cdot, T H \Lambda$ & $\%$ \%, २q &., .09 & & & $r, 111$ & · . ام الثانية & & & \\
\hline$\% \wedge, \vee Y r$ & $*_{\bullet}, 1 \vee q$ & & & & & r,.OY & _. [ م الثالثة & & & \\
\hline & & & & & & $\overline{1, \Lambda V \Gamma}$ & • . ام الرابعة & & & \\
\hline$\% \leqslant 9,0$. & $*_{\cdot,,}^{*}, Y Y$ & $\% r^{\prime}, \cdot, \cdot$ & $\cdot, \ldots 9$ & $\% 0^{0, \ldots}$ & $\cdot, \ldots r$ & $\cdot, \cdot \leq \leqslant \leq$ & •.. ام الاولى & \multirow{4}{*}{ الفرملة } & \multirow{12}{*}{ الارتكاز } & \\
\hline$\%\{Y, \wedge \uparrow$ & $*_{\cdot, ., Y .}$ & $\% 1 \leqslant, Y q$ & $\overline{., \ldots V}$ & & & $\cdot,, \varepsilon \vee V$ & · . ام الثانية & & & \\
\hline \multirow[t]{2}{*}{$\% r \varepsilon, r \wedge$} & $*_{., ., 1 T}$ & & & & &., 04 & • . (م الثالثة & & & \\
\hline & & & & & &.,.$T V$ & · . . ام الر ابعة & & & \\
\hline$\%$ \%१,०० & $*_{., .}^{*}, q^{\prime}$ & $\% Y Y, Y Y$ & $*_{\bullet}^{*, . \top .}$. & $\%$ \% & $*_{.}^{*}, .1 \wedge$ &.,.$V T$ & •. ام الاولى & \multirow{4}{*}{ زالدفع } & & \\
\hline \%१Y,r. & $\cdot, .11$ & $\%$ \%, $\{\varepsilon$ & , , r r & & &., .91 & . . ام الثانية & & & \\
\hline$\% 9,0$ \% & $\cdot, \ldots 9$ & & & & &., .94 & · . ( ام الثالثة & & & \\
\hline & & & & & &., $1 \cdot r$ & · . ام الرابعة & & & \\
\hline$\% \leqslant r, \varepsilon$. & ${ }^{*} .01111$. & $\%$ \% & $*_{*},, r_{q}$ & $\% 17,91$ & $\cdot, \cdot, r$. &., $11 \wedge$ & •. ام الاولى & \multirow{4}{*}{ المجموع } & & \\
\hline$\%$ \%Y,OA & *.Tा11. & $\% \uparrow, \varepsilon 0$ & $\cdot, \cdots 9$ & & &., $1 \Gamma \wedge$ & · . ام الثانية & & & \\
\hline \multirow[t]{2}{*}{$\% 10,10$} & $\cdot, \cdot Y Y$ & & & & & $\cdot, 1 \leqslant V$ & ل. (م الثالثة & & & \\
\hline & & & & & &., 179 & • . أ م الر ابعة & & & \\
\hline$\%$ \%,११ & $\cdot, \ldots \varepsilon$ & $\% 1 \cdot, \leqslant 0$ & $\cdot, .17$ & $\%$ \%, ^^ & $\cdot, \ldots V$ & $\cdot, 1 \leqslant 9$ & ·. ام الاولى & \multirow{4}{*}{\multicolumn{2}{|c|}{ زمن الطيران }} & \\
\hline$\%^{\vee}, \wedge$ & $\cdot, .11$ & $\% 10, \Sigma \mathrm{V}$ & ${ }^{*}, \cdot, Y Y$ & & & $\cdot, 1 \leqslant Y$ & . . ام الثانية & & & \\
\hline$\% \curlyvee, \vee \vee \uparrow$ & $\cdot, ., 11$ & & & & &., $17 \varepsilon$ & . . (م الثالثة & & & \\
\hline & & & & & & $\cdot, 104$ & ·. · م الر ابعة & & & \\
\hline$\% 1, \pi 4$ & Y,YOI & $\% \cdot$, or & $\cdot, \wedge \wedge$. & $\% \cdot, 0\}$ & $\cdot, \wedge 9$ & $170,1 \times 9$ & ·. ام الاولى & & & \\
\hline$\% \cdot, \wedge \Gamma$ & 1,471 & $\% \cdot, \cdot 1$ & $\cdot, \cdot 1 \cdot$ & & & $17 \varepsilon, Y Y 9$ & |. ام الثانية & بة الخلفية & زاوية الر & \\
\hline$\% \cdot, \wedge \Gamma$ & $\overline{I, r V I}$ & & & & & $17 \leqslant, Y \leqslant 9$ & •. (م الثالثة & الدفع ل الدق & & \\
\hline & & & & & & $17 Y, \lambda \vee \lambda$ & · . . ام الر ابعة & & & \\
\hline$\% 10,09$ & $1 \cdot, 1 \leqslant \varepsilon$ & $\% \backslash$ \%,^० & $9, \leqslant 07$ & $\% \backslash \leqslant, ऍ \wedge$ & $9, \wedge, r$ & $7 \lambda, Y\urcorner \varepsilon$ & •. ام الاولى & & & \\
\hline$\% 1, .7$ & $\cdot, \Delta \Gamma \mid$ & $\% \cdot, \leqslant 7$ & $\cdot, r \circ \lambda$ & & & $\vee \vee \Lambda, \cdot \vee \lambda$ & . . ام الثانية & ئة الامامية & زاوية & \\
\hline$\% 1,0 r$ & 1,119 & & & & & $V V, V Y$. & • . (م الثالثة & الدفع & $\cdots$ & \\
\hline & & & & & & $V \wedge, 9.9$ & •. . ام الرابعة & & & \\
\hline$\% r,, \ldots$ & $*_{., .07}$ & $\% 17,0$. & $*_{\cdot}^{*}, . \leq \leqslant$ & $\%{ }^{\circ}, \ldots$ &.,., $1 \Gamma$ & .,YTV & •. ام الاولى & & & \\
\hline$\% 10, \ldots$ & ${ }^{\star} \cdot, \cdot \leq Y$ & $\% 11,11$ & $\cdot, \cdot \Gamma 1$ & & & $\cdot, \Upsilon \wedge$ & · · ام الثانية & خطط & $\therefore$ & \\
\hline$\%$ \%,ov & $\cdot, ., 11$ & & & & & $\cdot, \pi \backslash 1$ & |. ام الثالثة & خطوه & 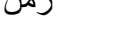 & \\
\hline & & & & & & ., RYY & • . (ام الرابعة & & & \\
\hline$\% r v, r v$ & ${ }^{*}, Y, Y$. & $\% \backslash \vee, Y q$ & $* 1,497$ & $\%\urcorner, .0$ & $\cdot, \sum \wedge 9$ & $\Lambda, \cdot V 4$ & •.ام الاولى & & & \\
\hline \%rr,7q & ${ }^{*} 1, V Y 1$ & $\% 11,90$ & $\cdot, 9 \cdot V$ & & & $\mathrm{~V}, 0 \wedge \mathrm{T}$ & . . ام الثانية & & & \\
\hline$\% 1 Y, 19$ & $\cdot, \wedge \backslash \leq$ & & & & & $7,7 \vee 9$ & · · م الثالثة & لحطوة & & \\
\hline & & & & & & $0, \wedge T \varepsilon$ & . . ام الرابعة & & & \\
\hline$\% 1 r, r_{4}$ & ${ }^{*} \cdot, Y \wedge \Lambda$ & $\%\{, \uparrow$. &., $1 \ldots$ & $\%$ \%,११ & $\cdot, \cdot \wedge V$ & r,IVY & •.. ام الاولى & & & \\
\hline$\% 9,7 \leqslant$ & $*_{*, Y, Y}$ & $\% \cdot, 7 \leqslant$ & $\cdot, \cdot, 1 \Gamma$ & & & $r, \cdot \wedge T$ & . . ام الثانية & $\therefore$ & 11 & \\
\hline$\% q, \cdot v$ & $*_{\cdot, / \wedge \wedge}$ & & & & & $T_{,} \cdot V Y$ & . . ام الثالثة & حطوه & طون & \\
\hline & & & & & & $\overline{l, \wedge \Lambda \varepsilon}$ & · . . ام الرابعة & & & \\
\hline$\%$ \%Y,, . & ${ }^{*},, ., 1 \Gamma \mu$ & $\% \leqslant, \Gamma_{O}$ & $\cdot, \ldots r$ & $\% \wedge, \vee$. & , , , $\varepsilon$ &., .01 & •.. ام الاولى & & & \\
\hline$\% \curlyvee \wedge, \backslash \leq$ & ${ }^{*} \cdot, \cdot 1 \vee \lambda$ & $\% \backslash\{, \Upsilon 9$ & $\cdot, \cdots V$ & & & $\cdot, \cdot \leq \vee$ & . . ام الثانية & زمن & & \\
\hline$\% r \cdot, \wedge r$ &., .11 & & & & &., .04 & . . ام الثالثة & الفرملة & & \\
\hline & & & & & & $\cdot, \cdot 7 \varepsilon$ & · . (م الر ابعة & & & \\
\hline$\%$ \%१,।r & $*_{\cdot, ., Y Y}$ & $\%$ \%.,09 &., .17 & $\% 1\{, v \mid$ &., .11 &.,.$\times 7$ & •. ام الاولى & & & الحطوة \\
\hline$\%$ \%YY,AY &., .11 & $\% 0,1 T$ &,$\ldots \varepsilon$ & & & $\cdot, \cdot \wedge \mathrm{V}$ & · . ام الثانية & زمن & زمن & \\
\hline$\% \vee, r r$ & $\cdot, \ldots V$ & & & & & $\cdot, .91$ & · . (م الثالثة & الدفع & الارتكاز & \\
\hline & & & & & &., .91 & · . ام الرابعة & & & \\
\hline$\% \curlyvee \wedge, \varepsilon \curlyvee$ & ${ }^{*} \cdot, ., 44$ & $\% \backslash\{, \cdot \varepsilon$ & $\cdot, \cdot 11$ & $\% 0, Y \uparrow$ & $\cdot, \ldots V$ & $\cdot, I T V$ & •..'ام الاولى & & & \\
\hline$\%$ Y, Vo & ${ }^{*} \cdot, ., 4 q$ & $\% \wedge, \Gamma \mu$ & $\cdot, .11$ & & & מזו, & • . ام الثانية & & & \\
\hline$\% \backslash Y, r \mid$ & $\cdot, \cdot 1 \wedge$ & & & & & $\cdot, 1 \leq \leqslant$ & · · ام الثالثة & المجموع & & \\
\hline & & & & & &., 174 & . . ام الرابعة & & & \\
\hline$\% 1, \leq 0$ & $\cdot, \cdot r$ & $\% \cdot, \cdot \cdot$ & $\cdot, \cdots$ & $\%$ \%, ro &,$\ldots v$ &., 104 & ·. . ام الاولى & طير طيران & زمن & \\
\hline
\end{tabular}




\begin{tabular}{|c|c|c|c|c|c|c|c|c|}
\hline \multicolumn{6}{|c|}{ فروق المتوسطات } & \multirow{3}{*}{ الحستوسطى } & \multirow{3}{*}{ السباقع } & \multirow{3}{*}{ المتغيرات } \\
\hline \multicolumn{2}{|c|}{. . ام الرابعة } & \multicolumn{2}{|c|}{. . ام الثالثة } & \multicolumn{2}{|c|}{.. ام الثاتية } & & & \\
\hline الفرقبة نسبة & الفرق & الفرقبة & الفرق & الفرق\%ة & الفرق & & & \\
\hline$\% 7,+7$ & $\cdot, \cdots 9$ & $\% \leqslant, 00$ & $\cdot, \cdots V$ & & & $\cdot, 1 \leqslant V$ & . . ام الثانية & \\
\hline \multirow[t]{2}{*}{$\% 1, \leqslant 0$} & $\cdot, \cdots r$ & & & & & $\cdot, 104$ & · · م الثالثة & \\
\hline & & & & & &., 107 & . . ام الر ابعة & \\
\hline$\% \cdot, \cdot r$ & $\cdot, \cdot r \Lambda$ & $\% 1,07$ & r,Or. & $\% 1, Y T$ & $1,9 \wedge 9$ & $171,9 \mathrm{YV}$ & ... ام الاولى & \multirow{4}{*}{ زاوية الركبة الخلفية - لحظة الدفع } \\
\hline$\% 1, Y \leq$ & $r, \cdot Y V$ & $\% \cdot, r r$ & $\cdot, 0 \leqslant 1$ & & & 174,917 & · . ام الثانية & \\
\hline \multirow{2}{*}{$\% 1,07$} & Y,071 & & & & & $17 \varepsilon, \varepsilon 0 V$ & . . (م الثالثة & \\
\hline & & & & & & $171,1 \wedge 9$ & · · ام الرابعة & \\
\hline$\% r, \ldots$ & 1,711 & $\% 9,1 r$ & V,rדr & $\% 0,07$ & $\Sigma, \leqslant 9$. & $\Lambda \cdot, \vee Y T$ & •. ام الاولى & \multirow{4}{*}{ زاوية الركبة الامامية } \\
\hline$\% \wedge,+1$ & $7,1 \cdot 1$ & $\% r, V \vee$ & $r, \wedge \vee r$ & & & Vד,ז & . . ام الثانية & \\
\hline \multirow[t]{2}{*}{$\% \backslash Y, Y \leq$} & $\wedge, 9 \wedge 1$ & & & & & VT,YTY & . . ام الثالثة & \\
\hline & & & & & & $\wedge r, r \leq r$ & · · م الر ابعة & \\
\hline$\% 1 r, O V$ & $* \cdot, \cdot r \wedge$ & $\%$ \%, r० & $\cdot, \cdot 11$ & $\% \cdot, \cdots$ & $\cdot, \ldots$ & $\cdot, r \wedge$. & ... ام الاولى & \multirow{4}{*}{ زمن الخطوة } \\
\hline$\% 1 \mathrm{T,OV}$ & $*,, \cdot r \wedge$ & $\%$ \%,ro & $\cdot, \cdot 11$ & & & $\cdot, Y \wedge$. & . . ام الثانية & \\
\hline \multirow{2}{*}{$\%\urcorner, \vee Y$} & $\cdot, \cdot r \cdot$ & & & & & $\cdot, Y q \wedge$ & ... ام الثالثة & \\
\hline & & & & & & $\cdot, \Pi \wedge$ & · · م الر ابعة & \\
\hline \%Yr,OV & ${ }^{*},, \wedge \leqslant Y$ & $\% 1 \cdot, \Sigma Y$ & $\cdot, \wedge) \leq$ & $\% \varepsilon, 1 T$ & D & $\vee, \wedge 10$ & ... ام الاولى & \multirow{4}{*}{ سر عة الخطوة } \\
\hline$\% r \cdot, r q$ & *1,OY. & $\% 7,0 \mathrm{~V}$ & $\cdot, \leqslant 94$ & & & $V, \Sigma 9 Y$ & · . ام الثانية & \\
\hline \multirow[t]{2}{*}{$\% \backslash \leqslant, 7 \wedge$} & $* 1, .4 \wedge$ & & & & & $v, \ldots$ & • . ام الثالثة & \\
\hline & & & & & & $0,9 \vee Y$ & · · م الر ابعة & \\
\hline$\% \varepsilon, 07$ & T,ITV & $\%$ \%, ६. & ., TTV & $\% \vee, r V$ & $r, 0 \ldots$ & $\varepsilon \vee, 0 \ldots$ & ... ام الاولى & \multirow{4}{*}{ عدد الخطوات (عدد) } \\
\hline$\% \backslash r, \wedge \wedge$ & $*_{0} 0,77 \mathrm{~V}$ & $\%\urcorner, \leqslant \leqslant$ & Y,ATr & & & $\varepsilon \varepsilon, \ldots$ & · · م الثانية & \\
\hline \multirow[t]{2}{*}{$\% 7, .0$} & Y,ATr & & & & & 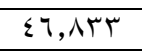 & . . ام الثالثة & \\
\hline & & & & & & $\leq 9,77 V$ & · · ام الرابعة & \\
\hline$\% \backslash \vee, \wedge \vee$ & $* Y, Y \wedge \wedge$ & $\% \vee, 9 \wedge$ & *I,.YY & $\%$ \%,Y7 & $\cdot, \Gamma \leqslant$. & IY,A.T & •.. ام الاولى & \\
\hline$\%$ \% , . A & *Y,TYA & $\% 1 \cdot, 94$ & *I, MTY & & & IY,E7T & . . ام الثانية & \\
\hline$\% 9,17$ & *1,Y74 & & & & & $I r, \wedge Y \wedge$ & . . ام الثالثة & الزمن (ت) \\
\hline & & & & & & $10, .94$ & • · ام الر ابعة & \\
\hline$\% 1 \leq, 9$. & $* 1,17 \leqslant$ & $\% \vee, r r$ & ${ }^{*} \cdot, 0 V T$ & $\% r, \vee q$ & $\cdot, Y \backslash \wedge$ & $V, \wedge) \leq$ & ... ام الاولى & \\
\hline$\% \backslash \vee, Y$. & $\left.{ }^{*}\right), r \wedge r$ & $\% 9, \wedge 0$ & ${ }^{*} \cdot, \vee \vee 91$ & & & A, & ·. . ام الثانية & 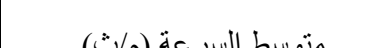 \\
\hline$\% \wedge, 17$ & $* ., 091$ & & & & & $V, Y \leq Y$ & · · م الثالثة & مسوسط السرعه (م/ت]) \\
\hline & & & & & & 7,70 & · · م الر ابعة & \\
\hline \%), & $*^{*}, \leq \uparrow$. & $\% \wedge, \vee \wedge$ & *., TYT & $\% \varepsilon, \vee 7$ & $\cdot, I V V$ & $r, V I r$ & ·. ام الاولى & \\
\hline$\%\urcorner, \wedge 9$ & $\cdot, r \leq r$ & $\%\{, Y)$ & $\cdot, 1 \leq 9$ & & & r,OT & ·. ام الثانية & \\
\hline$\%$ \%,Vq & $\cdot, .9 \leq$ & & & & & $r, r \wedge \Lambda$ & . . ام الثالثة & منوسط التردد (ح/ت) \\
\hline & & & & & & $r, r q 1$ & · . ( م الر ابعة & \\
\hline$\% \varepsilon, .0$ & $\cdot, \cdot \wedge 7$ & $\% 1,7 \pi$ & $\cdot, \cdot T \varepsilon$ & $\% \wedge, 1$. & ${ }^{*} \cdot,|\vee|$ & $r, 11$. & ... ام الاولى & \\
\hline$\% \backslash, Y \wedge$ & $*^{*}, Y \circ V$ & $\%\urcorner, \cdots$ & $\cdot, I T V$ & & & Y,YVA & . . ام الثانية & (1) : hill th \\
\hline$\% 0,7$. & $\cdot, 1 Y \cdot$ & & & & & $r, 1 \leq r$ & · · م الثالثة & مسوسط طول الحطوه (م) \\
\hline & & & & & & $T, \cdot Y T$ & . . ام الر ابعة & \\
\hline$\% 70,11$ & YrV,Yr & $\% \wedge r, r V$ & $*$ *..,11 & $\% \leqslant r, 90$ & $17 ., 11$ & שחז,ז & ... ام الاولى & \\
\hline$\% \backslash \leqslant, \vee$. & $V \vee, 11$ & $\%$ \% 7,79 & $1 \leq \cdot, \cdots$ & & & OY $\leq, \leq \leqslant \varepsilon$ & ... ام الثانية & انزيم كرياتين فوسفوكاينيز \\
\hline$\% 9, \leqslant 7$ & $7 Y, \wedge 9$ & & & & & $77 \varepsilon, \varepsilon \leqslant \varepsilon$ & ل · · ام الثالثة & $(\mathrm{u} / \mathrm{l}) \mathrm{CPK}$ \\
\hline & & & & & & $7.1,007$ & · · · م الرابعة & \\
\hline 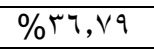 & IYT,YY & $\% 70, \cdot r$ & *YYT,II & $\% r \cdot, \cdot r$ & $1 \cdot r, \cdots$ & $r \leqslant r, 111$ & •... ام الاولى & \\
\hline$\% 0, Y)$ & Tr,YY & $\%$ \%ฯ, १Y & $1 r \cdot, 11$ & & & $\varepsilon \leqslant 7,111$ & ل . ام الثانية & انزيم لاكتيك ديهيدروجينيز LDH \\
\hline$\% \backslash \vee, 11$ & $97, \wedge 9$ & & & & & OTI,YYY & ل . . ام الثالثة & $(\mathrm{u} / \mathrm{l})$ \\
\hline & & & & & & פרף, & · . ام الرابعة & \\
\hline$\% \leqslant \vee q, r \wedge$ & $* 1, \ldots, 7 V$ & $\% \leq 94,1 \leq$ & $* 1.4,07$ & $\%$ \%। & $* \leqslant 0,11$ & $r 1, \ldots$ & •... ام الاولى & \\
\hline$\% \wedge \varepsilon, \cdot \varepsilon$ & $* 00,07$ & $\% \wedge \wedge, \varepsilon$. & $* 0 \wedge, \leqslant \leq$ & & & 77,111 & ل · · م الثانية & 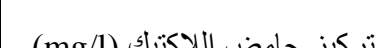 \\
\hline \%Y,rY & $r, \wedge \wedge q$ & & & & & $1 Y \leqslant, 007$ & ل · · ام الثالثة & حامض النحديك (mg/l/) \\
\hline & & & & & & $1 Y 1,77 V$ & . . ام الر ابعة & \\
\hline
\end{tabular}


يتضح من جدول ( • () و الخاص بأقل فرق معنوى لبنفرونى ونسبة الفروق فى المتغيرات البيو ميكانيكية لخطوة الجرى الأولى و الثانية بين مقاطع سباق .. متر حيث جاءت نسبة الفروق بين . . 1 م الاولى و الثانية مـا بين

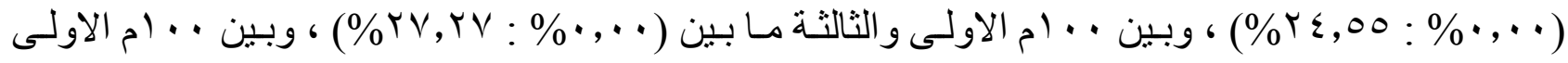

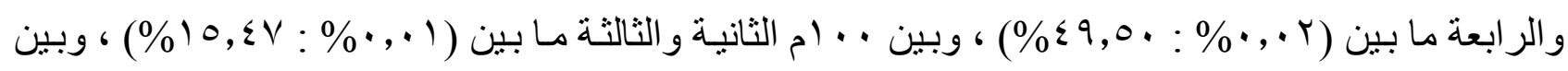

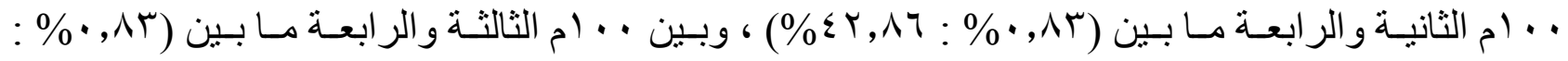

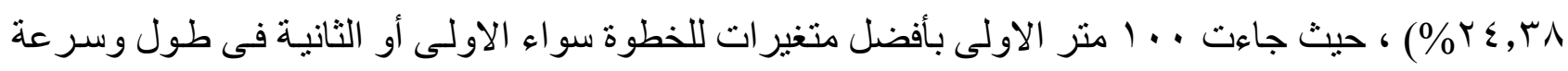

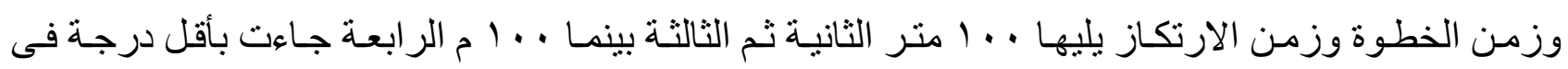

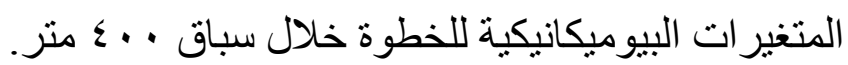

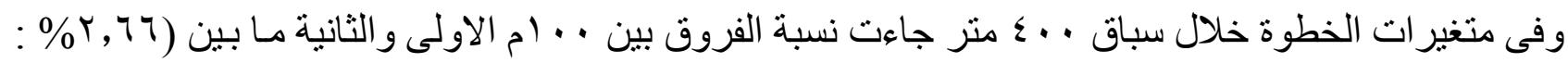

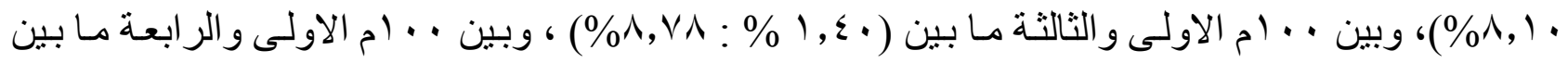

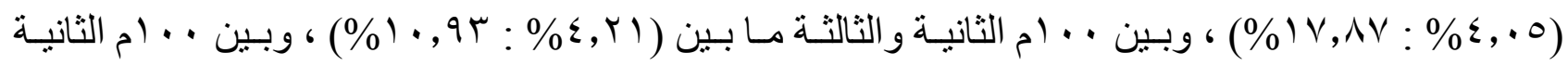

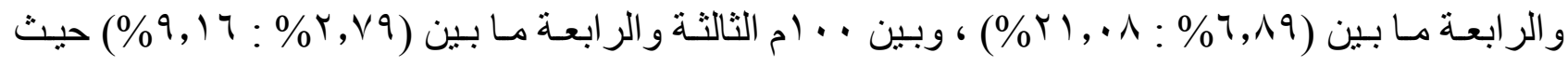
جاءت . . 1 متر الثانية بأقل عدد خطوات و أفضل زمن وطول للخطوة بينما جاءت . . . ( م الاولى بأفضل سر عة للخطوة وأعلى تردد بينما جاءت . . أمتر الاخبرة بأكبر عدد للخطوات و أعلى زمن و وأقل تردد و أقل

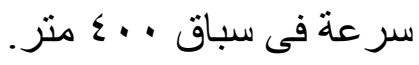

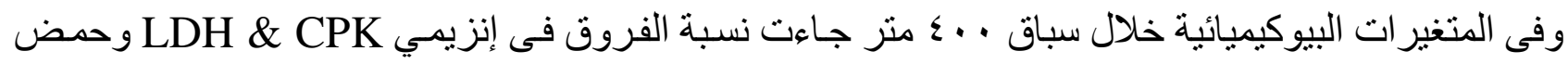

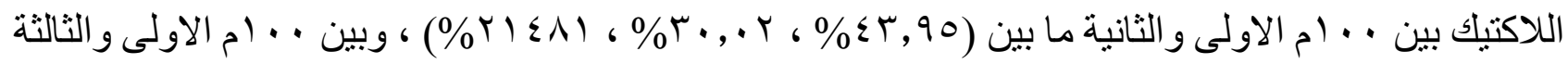
ما بين (Yr,

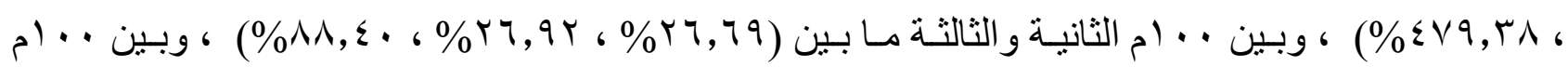

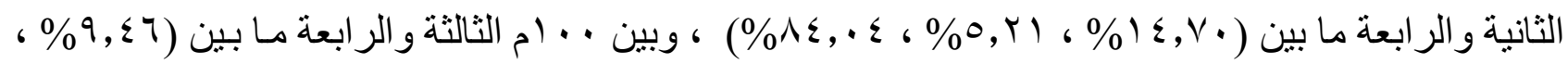

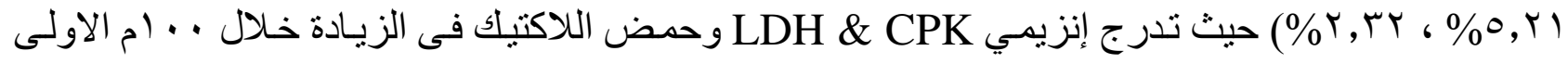

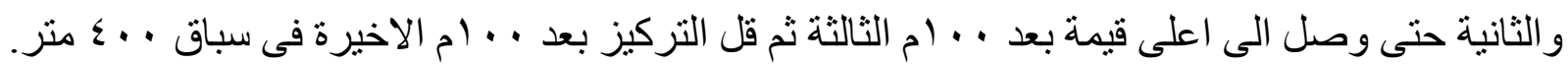


يتضح من الجداول السابقة لعرض نتائج البحث أن هناك زيادة ديناميكية فى تركيز مستوى حمض اللاكتيك

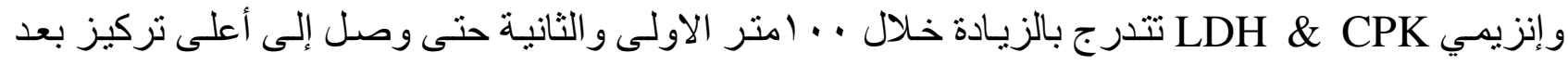

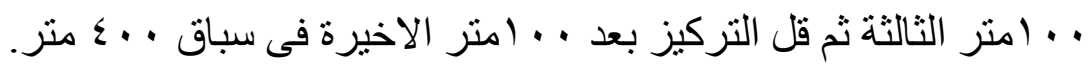

وتوجد علاقة ارتباط عكسية بين زيـادة تركيز حمض اللاكتيك و إنزيمي LDH \& CPK و المتغيرات

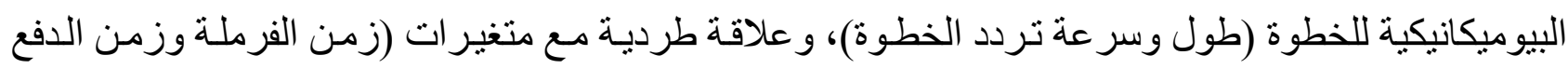

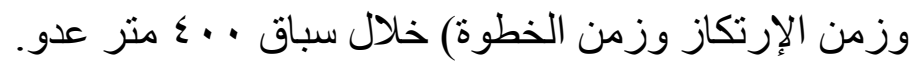

حيث جاءت . . 1 منر الاولى بأفضل متغير ات للخطوة سواء الاولى أو الثانية فى طول وسر عة وزمن

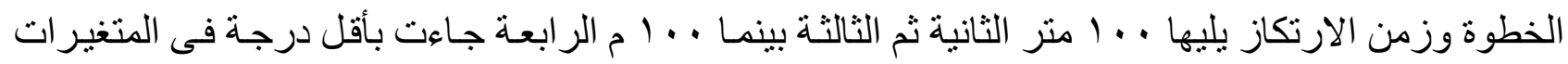

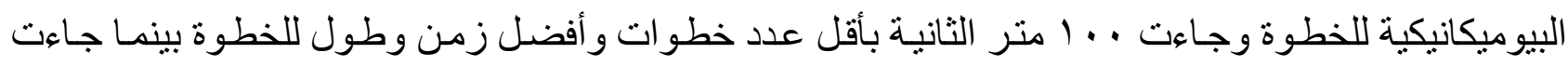

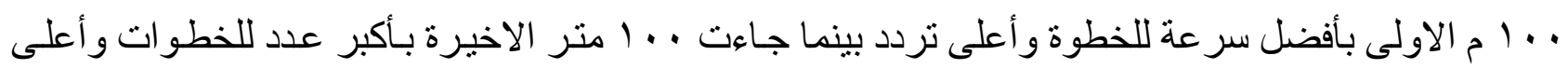
زمن و أقل تردد و أقل سر عة في سباق . . ع متر.

ومن خلال ذللك يظهر للباحثان تأثير كلا من حامض اللاكتيك و إنزيمي CPK ، LDH علي بعض متغير ات

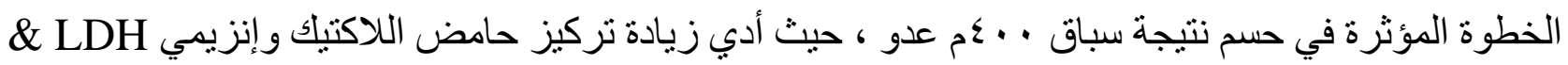
CPK ويذكر جير مي ريتشموند Jeremy R (1) (1) أن في مرحلة الإرتكاز يحدث نقص للسر عة للدى صفوة

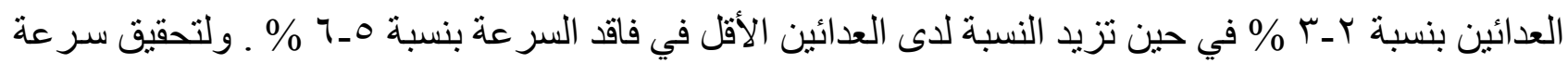

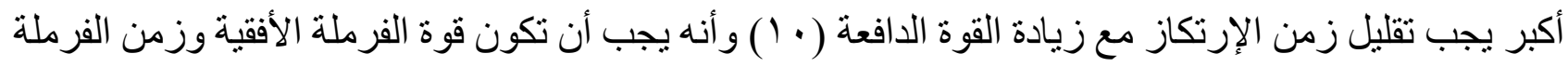

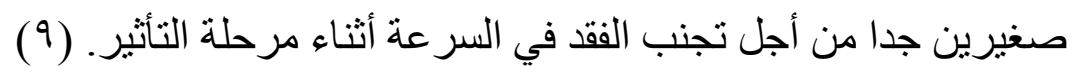

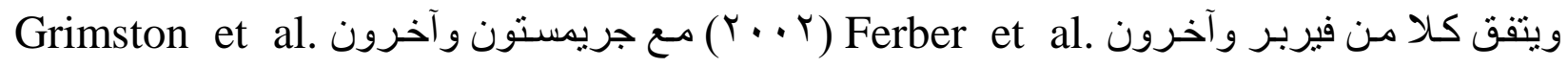

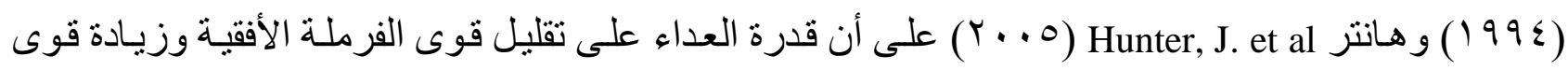

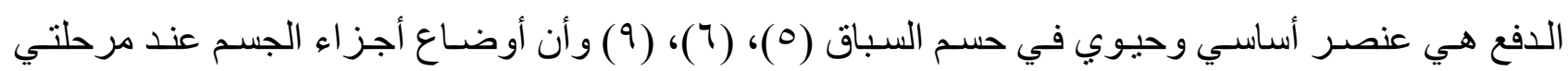

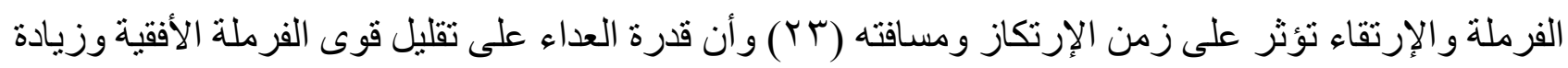

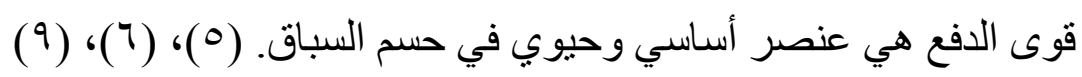
ولقد حدد مبلان كو وآخرون Milan Coh, et al (r . . Y) أن أهم الخصـائص البيوميكانيكيـة لخطوة العدو المؤثرة على السر عة القصوى هى زمن الإرتكـاز وزمن الفرملـة و أقل مقدار إندفاع ممكن لمرحلـة الفرملـة 
و أقصى مقدار إندفاع ممكن لمرحلة الدفع و الإحتفاظ بأقصى سر عة أفقية لمركز ثقل الجسم في مرحلة الإرتكاز (lV) الأمامي. (lV)

كما يرى الباحثان أن زيادة تركيز حامض اللاكتيك و إنزيمي CPK \& LDH قد أثر ا علي زمن الطيران

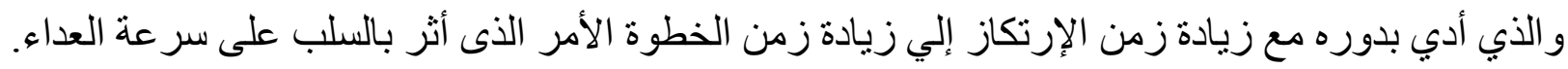

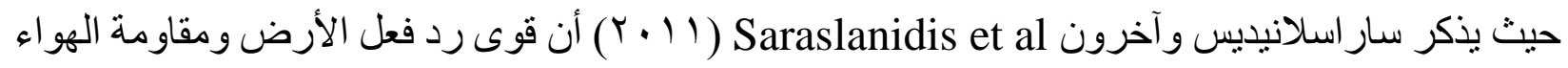
أثناء الإرتكاز تؤثر على زمن الطير ان ومسافته (T) (T) وأن مرحلة تناقص السر عة تتميز بزيادة طفيفة في أزمنة

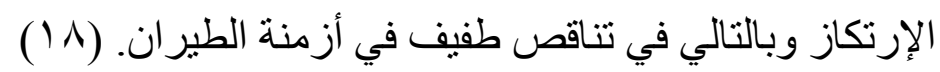
ويرى نوفاتثيك Novacheck (1991) أن سرعة العدو تزداد كلما كانت المدة الزمنية لمرحلة الإرتكاز

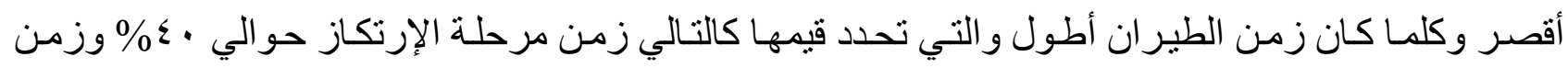

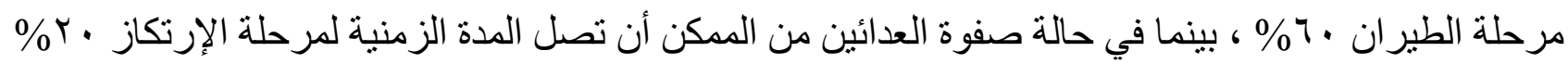

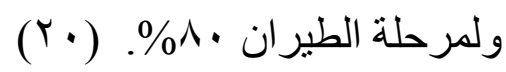

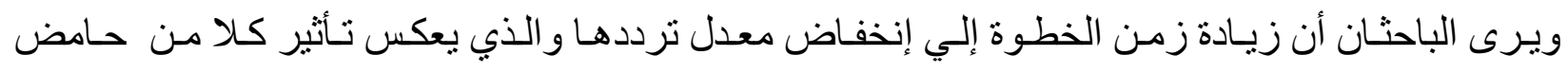

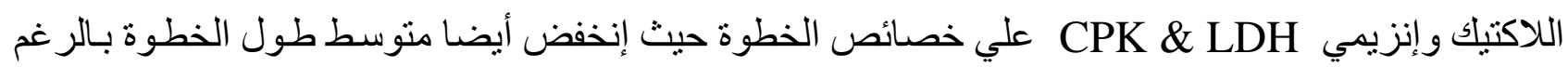

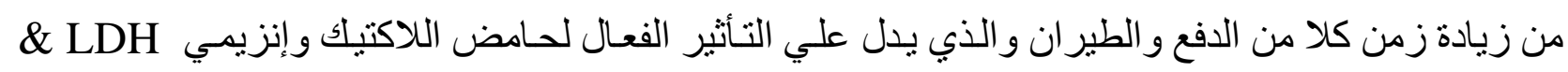

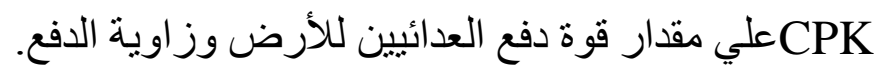

ويشير ميرو و آخرون Mero, A., et al (99 199 ) أنه عند عدو الثخص بسر عات مختلفة فان الزيادة في سر عة العدو ترتبط بزيادة كلا من طول وتردد الخطوة (7 (1) و وأن طول الخطوة محكوم بالقوة التى يبذلها العداء خلال فترة التلامس مع الأرض، وأن الطريقة المثالية لتحسن طول الخطوة ليست بتغيير الأسلوب ولكن بتحسين

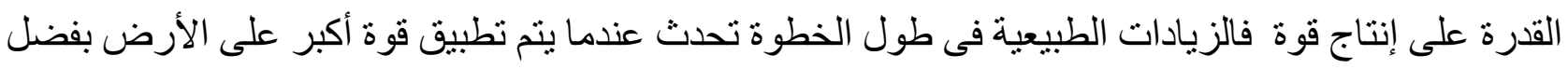

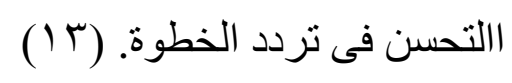

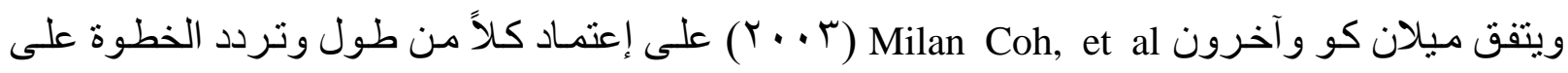

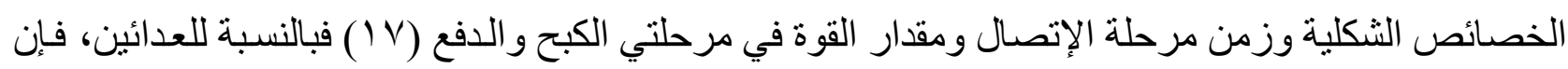

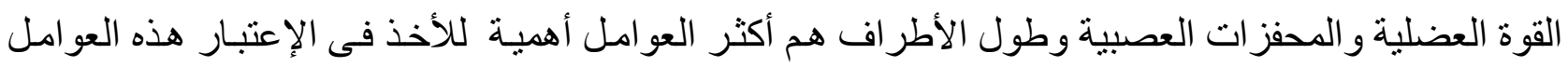

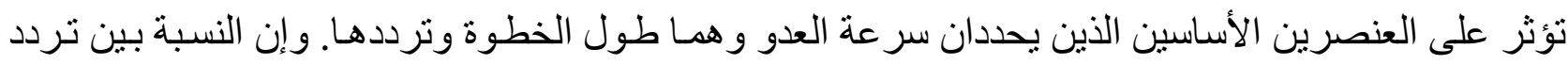

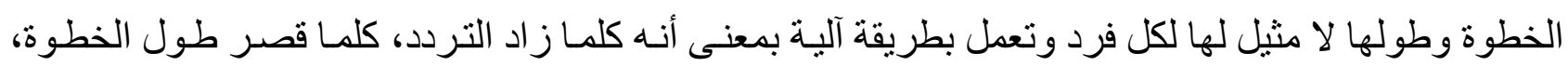

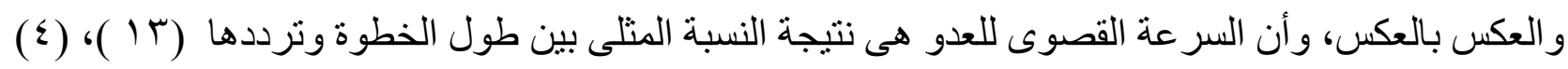


ويرى الباحثان أنه مع التغير ات السلبية لكلا من طول الخطوة وترددها حدث إنخفاض في منوسط سر عة الخطوة والذي أدي بدوره إلي زيادة الزمن الكلي للسباق و الذي يعكس الو اقع بتأثنير كلا من حامض اللاكتيك

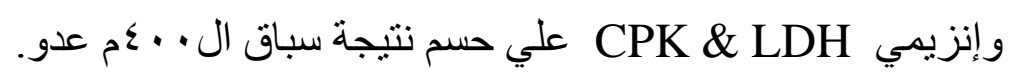

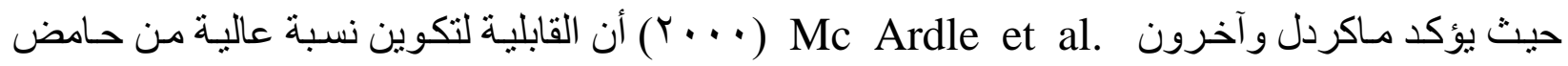

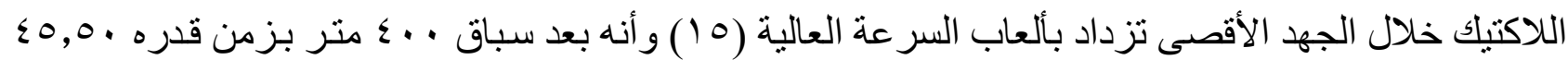

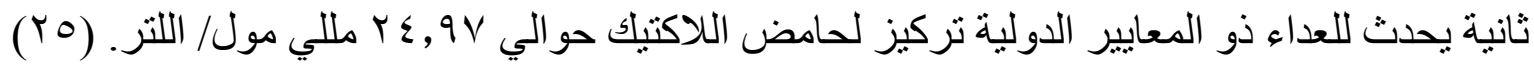

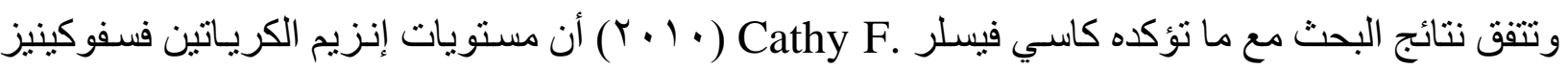
تزداد بعد التدريب، و هنالك عو امل عديدة تؤثر على إرتفاع نسبته بالدم خاصـة طول وشدة التدريب ، فالمعدل

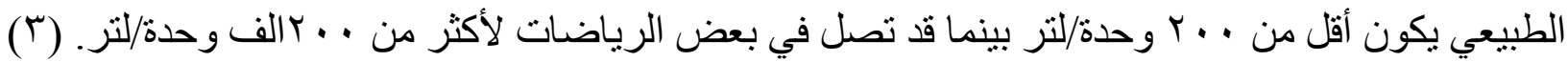

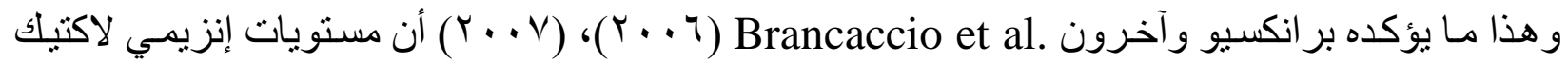
ديهيدروجينيز و الكرياتين فسفوكينيز تكون قليلة التركيز بالدم اثثـاء الراحة وهذا نـاتج عن تكسير وبنـاء الخلايـا داخليا بينما بعد التدريب الثديد يتم زيادتها بشكل كبير جدا (1)، (Y) وأن أكبر مؤثر تدريبي على زيادة إنزيم كرياتين فسفوكينيز هو تدريبات الثدة العالية والدة الطويلة وتدريبات الأثقال. (1) ويذكر مونجال و آخرون .Munjal et al (r (911) أن مستويات إنزيمي لاكتيك ديهيدروجينيز و الكرياتين

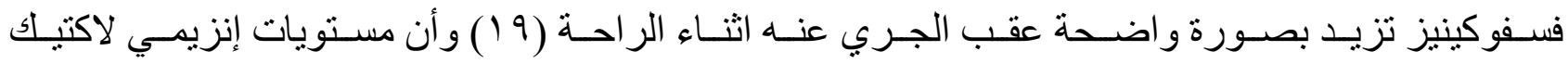
ديهيدروجينيز و الكرياتين فسفوكينيز في الدم تعطي مؤشر ا جيدا عن درجة التأقلم الأيضـي للعضلات الهيكلية للتندريب البني، فكلا الإنزيمين مشتركين في أيض العضلة وتركيز هم في الدم. (r) ويضيف تيتسو أوكاو او آخرون . Tetsuo Ohkuwa et al (9 1 1 ) أن هنـالك علاقة قويـة بين متوسط سرعة عدو سباق . .؛ متر ونشـاط مستوي إنزيم الكرياتين كينيز و اللاكتيك ديهيدروجينيز، كما يضيف أن العلاقة بين مستويات إنزيمي لاكتيك ديهيدروجينيز و الكرياتين كينيز في الدم أكثر فاعلية لتحديد مستوى التدريب دئين

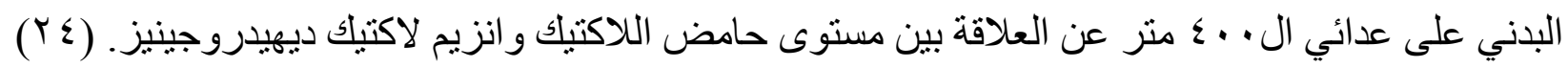
ومن خلال ما سبق من عرض ومناقشة النتائج يتضح تحقق فروض البحث أن هناك علاقة ارتباط معنوية بين متغير ات الخطوة وتغيرات تركيز حمض اللاكتيك و إنزيمي LDH \& CPK خلال سباق . . عم عدو ، و هناك فروق ذات دلالة معنوية فى متغيرات الخطوة وتركيز حض اللاكتيك و إنزيمي LDH \& CPK خلال مقاطع

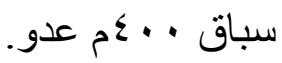




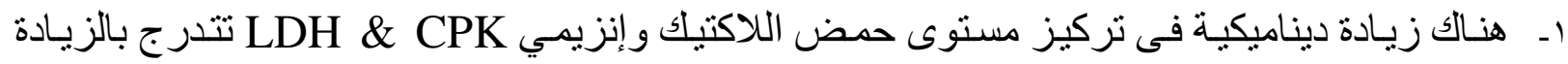

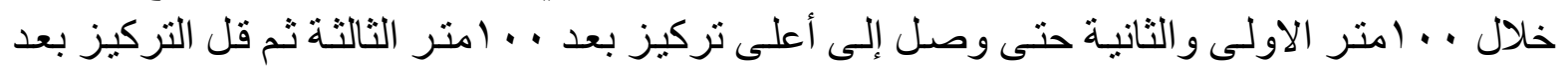

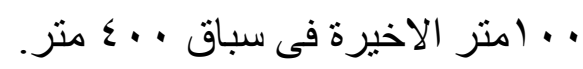

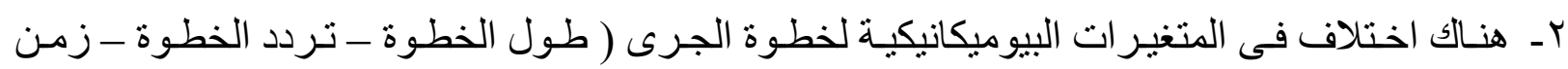

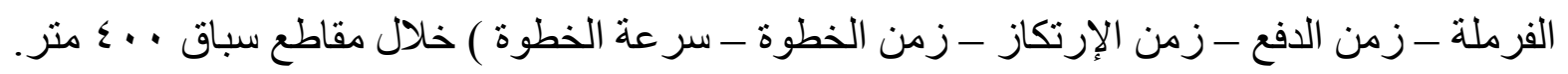

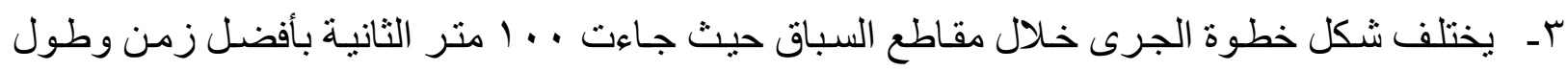

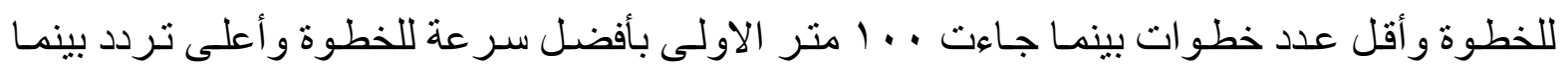

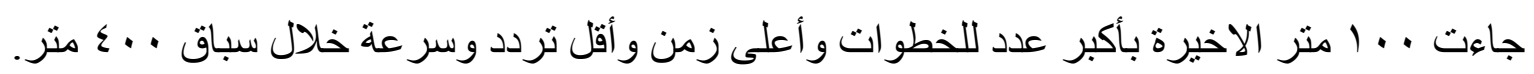

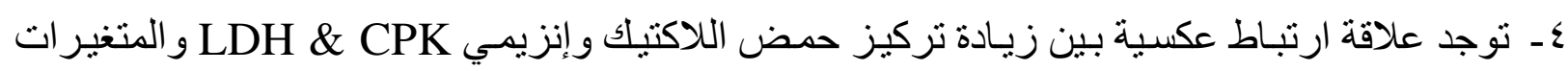

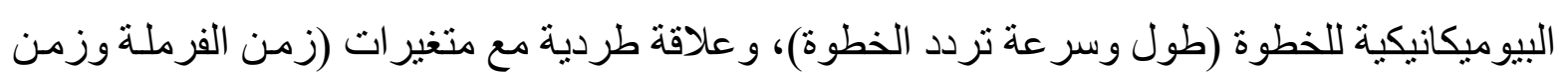

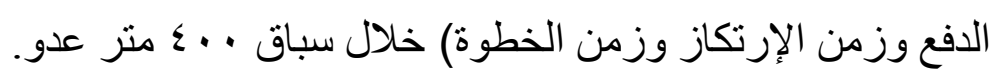

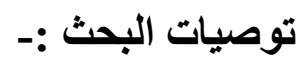

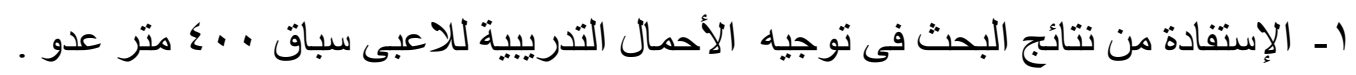

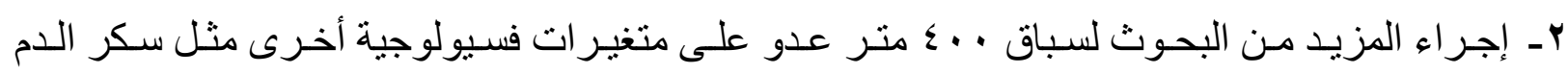

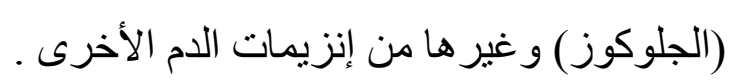

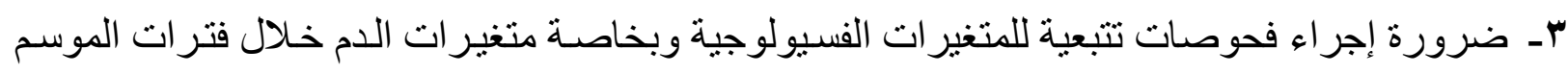
المختلفة لمتابعة حالة اللاعبين . ـ - إجر اء المزيد من البحوث على المتغيرات الكيناتيكية ومتغير ات القوة لخطوة العدو لمعرفة مدى الإرتباط

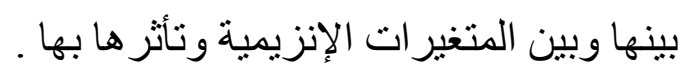

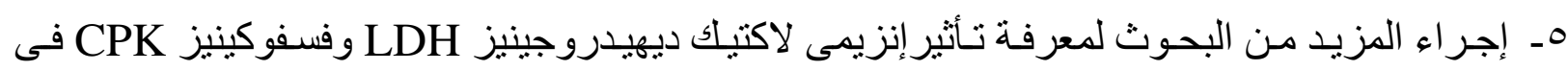

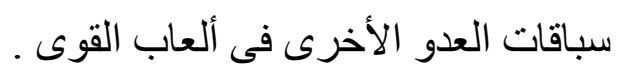


1 - Brancaccio

P1, Maffulli

$\mathrm{N}$, Limongelli FM

2 - Brancaccio

P1, Maffulli

$\mathrm{N}$, Limongelli FM

4 - COH, M. \& TOMAZIN, K
3 - Cathy Fieseler

: Creatine kinase monitoring in sport medicine. Br Med Bull. 2007;81-82:209-30. Epub 2007 Jun 14. http://www.ncbi.nlm.nih.gov/pubmed/17569697

: Monitoring of serum enzymes in sport J Sports Med. Feb; 40(2): 2006.

http://www.ncbi.nlm.nih.gov/pmc/articles/PMC249205 $0 /$

: What Runners Need to Know About Their Blood Test Results.Running times.OCTOBER 13, 2010 http://www.runnersworld.com/health/blood-test-resultsfor-runners

: Biomechanical characteristics of female sprinters during the acceleration phase and maximum speed phase. Modern Athlete and Coach, 43(4), 2005.

5 - Ferber, R.I., McClay- : Kinetic variables in subjects with previous lower Davis, I., Hamill, J., $\quad$ extremity stress fractures. Med Sci Sports Exerc, Pollard, C.D., \& 34(S5). 2002 McKeown, K.A.

6 - Grimston, S.K., Nigg, : External loads throughout a 45 minute run in stress B.M., Fisher, V., \& fracture and non-stress fracture runners. Journal of Ajemian, S.V. Biomechanics, 27,1994

7 - Guyton A. C : Anaerobic release of energy . In Text book of medical physiology . W. B. Saunders company. U. S. A. 1986.

8 - Haslett \& et al. : Principles and Practice of Medicine. Churchill Livingston, New York, 19th 2004 .

9 - Hunter, J.P., $\quad$ : Relationships between ground reaction force impulse Marshall, R.N., McNair, P.J. and kinematics of sprint-running acceleration. J Appl Biomech, 21(1), 2005 . 
10 - Jeremy Richmond

11 - Joshua Latham \& Darren Campbell

12 - Jürgen Schiffer

13 - Jürgen Schiffer

14 - kent, m.

15 - Mc Ardle W. D. , Katch F. I. , Katch V. L.
: Modelling a Sub-10 second 100m Sprinter Using Newton's Equations of Motion, IAAF NEW STUDIES IN ATHLETICS ISSUE 1/2.2011.

: How much can exercise raise creatine kinase level—and does it matter?. J Fam Pract. August;57(8): 2008 . http://www.jfponline.com/home/article/how-much-canexercise-raise-creatine-kinase-level-and-does-itmatter/86f4f4fd65053888a3d529aca00eb455.html

: $\quad$ The 400 metres, IAAF New Studies in Athletics • no. 2/2008, 2008

: The Sprints, IAAF New Studies in Athletics • no. $1 / 2009,2009$.

: Worterbuch sportwissenschaft und sportmedizin. Wiesbaden , 1998 .

: Lactate producing capacity In "Essentials of Exercise physiology . Lippincott Williams and Williams U. S. A. 2000.

16 - Mero, A., Komi, P.V., : Biomechanics of sprint running. A review. Sports \& Gregor, R.J. $\quad$ medicine (Auckland, NZ), 13(6), 1992.

17 - Milan Coh, Alex Dolenec, Bojan JoSt

: $\quad$ KINEMATIC, KINETIC AND ELECTROMYOGRAPHIC CHARACTERISTICS OF THE SPRINTING STRIDE OF TOP FEMALE SPRINTERS, Faculty of Sport, University of Ljubljana, Slovenia , 2003

18 - Moravec, P., Ruzicka, : The 1987 International Athletic Foundation/IAAF J., Susanka, P., Scientific Project Report: time analysis of the 100 Dostal, E., Kodejs, M., \& Nosek, M.

19 - Munjal DD, McFadden meters events at the II World Championships in Athletics. New Studies in Atheletics, 3, 1988 .

: Changes in serum myoglobin, total creatine kinase, lactate dehydrogenase and creatine kinase MB levels in 
JA, Matix

PA, Coffman

$\mathrm{KD}$, Cattaneo SM

20 - Novacheck, T. runners. Clin Biochem. Jun;16(3): 1983 .

http://www.ncbi.nlm.nih.gov/pubmed/6851084

: The biomechanics of running. Gait \& posture, 7(1), 1998.

21 - Paulo Jorge \& Victor : Speed strength endurance and 400m performance, Manuel IAAF New Studies in Athletics • no. 4/2004, 2004.

22 - Robergs, R.A. \& Roberts, S.O

: Fundamental principles of Exercise physiology for fitned, proormance and health, mcgraw - hill publishers . Bostn , 2000

23 - Saraslanidis, P.J., $\quad$ : The effect of different first 200-m pacing strategies on Panoutsakopoulos, blood lactate and biomechanical parameters of the 400V., Tsalis, G.A.. \& m sprint. Eur J Appl Physiol. 111(8), 2011 .

Kyprianou, E.

24 - Tetsuo Ohkuwa, Mitsuru Saito, Mihar u Miyamura

\section{5 - William Black}

: Plasma LDH and CK activities after $400 \mathrm{~m}$ sprinting by well-trained sprint runners . European Journal of Applied Physiology and Occupational Physiology.September, Volume 52, Issue 3, 1984 http://link.springer.com/article/10.1007\%2FBF0101521 3\#page1

: TRAINING FOR THE 400m, TRACK COACH \#102 (Winter), 1988 .

26 : http://kidshealth.org/parent/system/medical/test_ldh.html Date 17/10//2016

27 : http://en.wikipedia.org/wiki/Lactate_dehydrogenase Date 17/10//2016 